\title{
Evolution of the patellar sesamoid bone in mammals
}

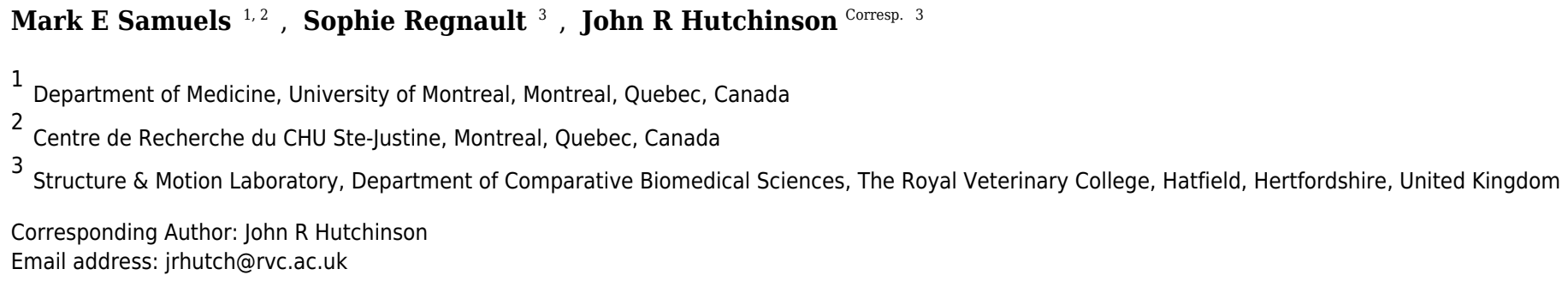

The patella is a sesamoid bone located in the major extensor tendon of the knee joint, in the hindlimb of many tetrapods. Although numerous aspects of knee morphology are ancient and conserved among most tetrapods, the evolutionary occurrence of an ossified patella is highly variable. Among extant (crown clade) groups it is found in most birds, most lizards, the monotreme mammals and almost all placental mammals, but it is absent in most marsupial mammals as well as many reptiles. Here we integrate data from the literature and first-hand studies of fossil and recent skeletal remains to reconstruct the evolution of the mammalian patella. We infer that bony patellae most likely evolved between four to six times in crown group Mammalia: in monotremes, in the extinct multituberculates, in one or more stem-mammal genera outside of therian or eutherian mammals, and up to three times in therian mammals. Furthermore, an ossified patella was lost several times in mammals, not including those with absent hindlimbs: once or more in marsupials (with some re-acquisition), and at least once in bats. Our inferences about patellar evolution in mammals are reciprocally informed by the existence of several human genetic conditions in which the patella is either absent or severely reduced. Clearly, development of the patella is under close genomic control, although its responsiveness to its mechanical environment is also important (and perhaps variable among taxa). Where a bony patella is present it plays an important role in hindlimb function; especially in resisting gravity by providing an enhanced lever system for the knee joint. Yet the evolutionary origins, persistence and modifications of a patella in diverse groups with widely varying habits and habitats -- from digging to running to aquatic, small or large body sizes, bipeds or quadrupeds -- remain complex and perplexing, impeding a conclusive synthesis of form, function, development and genetics across mammalian evolution. This meta-analysis takes an initial step toward such a synthesis by collating available data and elucidating areas of promising future inquiry. 
1 Evolution of the patellar sesamoid bone in mammals

2 Samuels, Mark E., ${ }^{1,2}$ Regnault, Sophie ${ }^{3}$ and Hutchinson, John R. ${ }^{3 *}$

$3{ }^{1}$ Department of Medicine, University of Montreal, Montreal, Quebec, H3T 1C5, Canada

$4{ }^{2}$ Centre de Recherche du CHU Ste-Justine, Montreal, Quebec, H3T 1C5, Canada

$5{ }^{3}$ Structure \& Motion Lab, Department of Comparative Biomedical Sciences, The Royal

6 Veterinary College, Hawkshead Lane, Hatfield, Hertfordshire, AL9 7TA, United Kingdom.

7 *Corresponding author

8 Running head: Patellar evolution in mammals 


\section{Abstract}

10 The patella is a sesamoid bone located in the major extensor tendon of the knee joint, in the

11 hindlimb of many tetrapods. Although numerous aspects of knee morphology are ancient and

12 conserved among most tetrapods, the evolutionary occurrence of an ossified patella is highly

13 variable. Among extant (crown clade) groups it is found in most birds, most lizards, the

14 monotreme mammals and almost all placental mammals, but it is absent in most marsupial

15 mammals as well as many reptiles. Here we integrate data from the literature and first-hand

16 studies of fossil and recent skeletal remains to reconstruct the evolution of the mammalian

17 patella. We infer that bony patellae most likely evolved between four to six times in crown group

18 Mammalia: in monotremes, in the extinct multituberculates, in one or more stem-mammal genera

19 outside of therian or eutherian mammals, and up to three times in therian mammals. Furthermore,

20 an ossified patella was lost several times in mammals, not including those with absent hindlimbs:

21 once or more in marsupials (with some re-acquisition), and at least once in bats. Our inferences

22 about patellar evolution in mammals are reciprocally informed by the existence of several human

23 genetic conditions in which the patella is either absent or severely reduced. Clearly, development

24 of the patella is under close genomic control, although its responsiveness to its mechanical

25 environment is also important (and perhaps variable among taxa). Where a bony patella is present

26 it plays an important role in hindlimb function; especially in resisting gravity by providing an

27 enhanced lever system for the knee joint. Yet the evolutionary origins, persistence and

28 modifications of a patella in diverse groups with widely varying habits and habitats -- from

29 digging to running to aquatic, small or large body sizes, bipeds or quadrupeds -- remain complex

30 and perplexing, impeding a conclusive synthesis of form, function, development and genetics

31 across mammalian evolution. This meta-analysis takes an initial step toward such a synthesis by

32 collating available data and elucidating areas of promising future inquiry. 
34 This meta-analysis addresses the evolution of the ossified patella (tibial sesamoid or "kneecap"

35 bone) in mammals. Our focus was on the evolutionary pattern of how bony patellae evolved in 36 the mammalian lineage, as evidence of osseous patellae is simplest to interpret. However, as explained further below we also consider non-bony sesamoids to also be potential character states of the patellar organ; vexing as the form, fossil record and ontogeny (and thus homology) of those soft-tissue structures are. We compiled voluminous literature and firsthand observational data on the presence or absence of the osseous patella in extinct and extant mammals, then conducted phylogenetic analysis of patellar evolution by mapping these data onto a composite phylogeny of mammals (Kielan-Jaworowska et al. 2004; Luo 2007a; Luo 2007b) using multiple phylogenetic optimization methods. We used the results to address patterns of acquisition and loss (i.e. gain and loss of ossification) of this structure within Mammaliaformes. In particular, we investigated whether an ossified patella was ancestrally present in all crown group Mammalia, and lost in particular groups especially marsupials (Metatheria), or whether it evolved multiple times in separate crown clades. Furthermore, if the bony patella had multiple origins, how many times was it gained or lost, and what did it become if it was lost (such as a vestigial fibrocartilage versus complete loss, without any evidence of a sesamoid-like tissue within the patellar tendon)? These were our study's key questions. We provide some broader context here first.

Some aspects of the morphology of the knee in tetrapods (four-legged vertebrates bearing limbs with digits) are evolutionarily ancient. Tetrapods had their ancestry amongst lobe-finned sarcopterygian fish, in which jointed, muscular fins transitioned into limbs. Early stages of distinct bony articulations between the femur and tibia-fibula are evident in the hind fins/limbs of Devonian ( $\sim 370$ million years ago; Mya) animals such as Eusthenopteron, Panderichthys, and Ichthyostega (Ahlberg et al. 2005; Andrews \& Westoll 1970; Boisvert 2005; Dye 1987; Dye 2003; Haines 1942). These fossil sarcopterygians also have subtle differences between the homologous joints in the pectoral fin/forelimb and the pelvic fin/hindlimb, indicating that specification of forelimb/hindlimb identity was already in place (Boisvert 2005; Daeschler et al. 2006; Shubin et al. 2006). Furthermore, the morphology of the forelimb and hindlimb joints indicates divergent functions of these limbs, with the forelimb evolving into a more "terrestrialized" capacity earlier than the hindlimb (Pierce et al. 2012). Developmental and morphological modifications to the hindlimb and particularly the mid-limb joint between the stylopod and zeugopod continued, until a recognizable knee articulation of almost modern, derived aspect arose in tetrapods of the Carboniferous period, 350 Mya (Dye 2003).

Sesamoids are best defined as "skeletal elements that develop within a continuous band of regular dense connective tissue (tendon or ligament) adjacent to an articulation or joint" (Vickaryous \& Olson 2007). The tibial patella is a sesamoid bone that arises during development within the main extensor tendon of the knee, subsequently 'dividing' it (though there remains some continuity) into the quadriceps and patellar tendons (the latter is sometimes inappropriately called the patellar ligament) (Bland \& Ashhurst 1997; Fox et al. 2012; Pearson \& Davin 1921a; Tecklenburg et al. 2006; Tria \& Alicea 1995; Vickaryous \& Olson 2007). These tendons span from the quadriceps muscle group to the tibia (Fig. 1). The patella itself tends to be incorporated mainly into the vastus muscles of the quadriceps in mammals, with the tendon of $\mathrm{M}$. rectus femoris lying more superficial to them (Tria \& Alicea 1995), with variable degrees of attachment to it (Jungers et al. 1980). Hereafter, the term "patella" implies ossification and hindlimb localization unless otherwise specified (some literature inconsistently and confusingly refers to non-ossified cartilaginous structures in this location as patellae - this homology in many cases needs better 
79

80

81

82

83

84

85

86

87

88

89

90

91

92

93

94

95

96

97

98

99

100

101

102

103

104

105

106

107

108

109

110

111

112

113

114

115

116

117

118

119

120

121

122

123

124 testing), and implicitly refers to either a single patella or the left and right patellae normally present in an individual. There is an "ulnar patella" in the forelimbs of some taxa (notably lizards, but also some frogs, birds and mammals (Barnett \& Lewis 1958; Haines 1940; Maisano 2002a; Maisano 2002b; Pearson \& Davin 1921a; Pearson \& Davin 1921b; Romer 1976; Vanden Berge \& Storer 1995; Vickaryous \& Olson 2007)) but a full discussion of this enigmatic structure is beyond the scope of this study. Figure 2 depicts the anatomical orientations used throughout this study to refer to tetrapod limbs.

The patella appears broadly similar amongst mammals possessing it, as far as has been studied, although it varies greatly in size, generally in accordance with body size. It ossifies endochondrally; from a cartilaginous precursor (i.e. anlage (Vickaryous \& Olson 2007)); relatively late in gestation (e.g. sheep, goats (Harris 1937; Parmar et al. 2009)) or sometime after birth (e.g. rabbits, rats, mice, humans (Bland \& Ashhurst 1997; Clark \& Stechschulte 1998; Patton \& Kaufman 1995; Spark \& Dawson 1928; Tria \& Alicea 1995; Walmsley 1940)). Very recently, the development of the patella in mouse embryos was re-examined and the claim made that the patella develops as a process that branches off the femur, strongly influenced by mechanical loading in that region (Eyal et al. 2015). Whether this truly happens as described in mice, let alone other mammals, and whether it can be accepted as unexpected support for the "traction epiphysis" origin of patellar sesamoids (e.g. Pearson \& Davin, 1921a,b), remains to be determined, but the surprising results deserve attention. The general form of the osseous patella in mammals is a hemispherical structure, with a superficial surface (covered by fibrocartilage (Clark \& Stechschulte 1998) and quadriceps tendon fibres (Bland \& Ashhurst 1997)) and a deep surface which articulates with the femur, gliding along the patellar sulcus or groove in that bone. In maturity, the patella is composed of an outer lamellar cortex enclosing an inner cancellous bone structure with marrow spaces, and has an articular hyaline cartilage lining on the deep surface for articulation with the patellar sulcus (groove) of the femur (Benjamin et al. 2006; Clark \& Stechschulte 1998; Vickaryous \& Olson 2007).

The vastus muscles' tendons (especially M. vastus intermedialis) may have a fibrocartilaginous region at the approximate position of the patella, called the "suprapatella" or "patelloid" (Fig. 1). The latter two terms are sometimes used synonymously, though "suprapatella" is more usual when an osseous patella is also present, and "patelloid" when it is not. The suprapatella is described as proximal to the patella, occasionally with a fat pad interposed between it and the ossified patella (Fig. 1), whilst the patelloid is described as occupying the same approximate region that a bony patella would (though absence of a patella makes this difficult to objectively assess) (Bland \& Ashhurst 1997; Jungers et al. 1980; Ralphs et al. 1991; Ralphs et al. 1998; Ralphs et al. 1992; Reese et al. 2001; Walji \& Fasana 1983). It is not clear whether the fibrous patelloid in some marsupials (and perhaps some bats (Smith et al. 1995)) is homologous to the suprapatella, equivalent to an evolutionarily reduced patella, or an independently occurring structure. We revisit this problem later in this study.

The human patellar anlage is first visible at O'Rahilly stage 19, and chondrifies at stage 22 . Ossification begins 14 weeks after birth (Merida-Velasco et al. 1997a; Merida-Velasco et al. 1997b; Tria \& Alicea 1995), but is not grossly visible until 4-6 years of age (when multiple, eventually-coalescing centres of ossification can be seen radiographically (Ogden 1984)) and sometimes not in its fully ossified form until adolescence. The patella is the only sesamoid bone counted regularly among the major bones of the human body (Vickaryous \& Olson 2007), although there are other, much smaller sesamoids in the hands and feet (and in some cases even the spine (Scapinelli 1963)). The pisiform is often considered a sesamoid and deserves further 
125 attention in a broad context similar to this study's. Other small sesamoids, such as the lunula, 126 fabella, cyamella and parafibula, also occur in the knee joint in many tetrapod species including 127 some mammals (Fig. 1); these occur sporadically in humans (Pearson \& Davin 1921a; Sarin et al. 128 1999).

129 The patella is covered by the thickest layer of articular cartilage in the human body (Palastanga et 130 al. 2006). The patella may thus also play a protective role for the underlying joint architecture 131 (Haines 1974), in addition to protecting the patellar tendon from excessive compressive stresses 132 (Giori et al. 1993; Sarin \& Carter 2000a; Wren et al. 2000). The patellar tendon itself, to the 133 extent that its properties are known for some species (e.g. humans), is stiff and strong, able to 134 withstand about twice as much stress as typical knee joint ligaments and enduring strains (i.e. 135 lengthening) of up to 11-14\% (Butler et al. 1986). Regional variations in the microscopic 136 anatomy of the human patella have also been recognised, for example in tissue thickness and 137 nerve arrangement, which may reflect load distribution (Barton et al. 2007; Eckstein et al. 1992; 138 Toumi et al. 2006; Toumi et al. 2012). There is convincing evidence from numerous species that 139 excessive loads on the patella can lead to degeneration of the articular cartilages and damage to 140 the underlying bone, producing osteoarthritis (Aglietti \& Menchetti 1995; Hargrave-Thomas et 141 al. 2013; Tria \& Alicea 1995), so those regional variations of patellar structure are likely 142 important. Similarly, the tissues involved in anchoring the patellar tendon to the proximal and 143 distal surfaces of the patella as well as to the proximal tibia (tuberosity/tubercle) vary in their 144 composition and presumably are adapted, and exhibit phenotypic plasticity, to reduce the risk of 145 tendon avulsion from the bone (Evans et al. 1991). Reduction of a bony patella to soft tissue 146 presumably reduces its ability to act as a gear or lever (Alexander \& Dimery 1985).

147 Functions of the patella notwithstanding, there was once some enthusiasm for its outright 148 removal for treatment of certain joint problems. Patellectomy was first performed in 1860 and for some time was an established treatment option for several conditions (Pailthorpe et al. 1991; Sweetnam 1964). However, partial and complete patellectomies are now considered as last resort salvage procedures; this is also the mainstream view of the veterinary profession (Langley-Hobbs 2009). The historical lack of clarity on the pros and cons of patellectomy was summarised eloquently by The Lancet, stating, "Sadly, most of our interventions on the patella are empirical, and are supported more by the enthusiasm of proponents than by a very deep knowledge of the biology or biomechanics of this unusual joint. The knee cap could do with more scientific attention" (Editors 1992).

157 The latter complaint regarding the dearth of scientific attention to form, development, function 158 and clinical treatment of the patella applies even more so to non-human tetrapods. One exception 159 is a study that measured the inter- and intra-specific variability of the patellae and other bones 160 (Raymond \& Prothero 2012). The latter study found generally greater variation in patellae (and 161 other sesamoids) vs. "normal" long bones. The inference was that this greater variability might pertain to the "intermembranous" [sic- intramembranous] development of sesamoids, vs. an endochondral location in long bones. However, the patella and most other major limb sesamoids of mammals are pre-formed in cartilage and thus clearly are endochondral bones (Farnum 2007). Yet the latter study reinforces that sesamoids are more variable than most other bones, in part due to their mechanical environment, in part due to their embedding in soft tissues (themselves quite variable) such as tendons and ligaments (Bland \& Ashhurst 1997; Clark \& Stechschulte 1998) and perhaps due to other factors not yet understood. This uncertainty about the causes of 170 and function in vivo, as follows. 
171 Where a patella is present in its typical form, its primary function is to modify the mechanical

172 advantage (ratio of output force to muscle force) at the knee joint, by increasing the moment arm

173 of the tendon in which it is embedded and thereby altering the amount of force needed from the

174 quadriceps muscles in order to generate a particular moment (torque; rotational force) about the

175 knee joint (Alexander \& Dimery 1985; Fox et al. 2012; Haines 1974; Heegaard et al. 1995;

176 Herzmark 1938; Howale \& Patel 2013; Tecklenburg et al. 2006). In humans, the patella causes

177 the quadriceps muscle group's moment arm about the knee to increase as the knee becomes more

178 extended, causing the amount of quadriceps muscle force required per unit of patellar tendon

179 force (i.e. at the insertion onto the tibial tubercle) to vary significantly across knee joint flexion-

180 extension (Aglietti \& Menchetti 1995; Fellows et al. 2005). By articulating with the femur, the

181 patella also transmits some forces of the quadriceps muscle group directly onto the femur (the

182 patellofemoral joint reaction force); forces which can reach a maximum of 20-25 times body

183 weight (Aglietti \& Menchetti 1995).

184 The mobility of the patella is an important aspect of its function. While, in humans, the patella mostly flexes and extends relative to the femur as the knee is flexed and extended, it also translates and pitches (tilts) and rolls (Aglietti \& Menchetti 1995; Fellows et al. 2005), leading to variable contact between the patella and femur that is reflected in the angled facets of the human patella (Lovejoy 2007). In contrast to the situation in humans (as well as in early hominins such as Australopithecus), in chimpanzees and presumably many other primates (as well as other taxa such as sheep (Bertollo et al. 2012; Bertollo et al. 2013)), the patella remains in tight articulation with the femur throughout the knee's range of motion, reducing patellofemoral stresses especially when the knee is strongly flexed, as it habitually is in those non-human primates (Lovejoy 2007). Other primates show varying degrees of specialization of patellar morphology that alter the moment arm of the patellar tendon, with great apes apparently having a patella most specialized for widely varying knee joint postures (Pina et al. 2014). It has been claimed that in hominids and ursids (bears) alike, there is an association between plantigrady (flat-footedness), increased knee range of motion, and patellar mechanics (Lovejoy 2007); that is an interesting hypothesis that could be rigorously tested.

In the elbow of humans and other mammals, there is an extension of the ulna called the olecranon (process), which serves a lever-like function analogous to that of the patella (Herzmark 1938). However, a mobile sesamoid bone like the patella has a more flexible ("dynamic gearing") function in improving mechanical advantage compared with an immobile retroarticular process like the olecranon (Alexander \& Dimery 1985). There tends to be an inverse relationship between mechanical advantage and speed of joint motion (Hildebrand 1998), thus a high mechanical advantage is not necessarily useful in all cases, which may in part explain the variable occurrence, size and shape of the patella in animals with different lifestyles and modes of locomotion. Biomechanical studies of primates (Lovejoy 2007; Pina et al. 2014) and domesticated mammalian species (e.g. dogs (Griffith et al. 2007; Kaiser et al. 2001), sheep (Bertollo et al. 2012; Bertollo et al. 2013), horses (Schuurman et al. 2003; Wentink 1978)) have contributed some knowledge of how the patella functions in these groups, or in individual species, but a general "functional synthesis" for the patella is still lacking.

212 De Vriese performed pioneering comparative analyses and attempted syntheses of patellar size

213 and morphology in comparison to other leg bones, between species and among multiple

214 individuals in some species (De Vriese 1909). No clear correlations were observed between the

215 size of the patella and other major hindlimb bones (femur, tibia, and fibula). A correlation was 
216 claimed between the sizes of the patella and the talus (or intermedium) in the ankle, although no

217 clear, plausible mechanistic/functional justification was suggested and no statistical analyses

218 were performed. Somewhat oddly, no relationship was evident between the size and shape of the

219 patella and the femoral patellar groove (De Vriese 1909). The more restricted but quantitative

220 analysis of Valois (Valois 1917) focused mainly on primates and challenged many of De Vriese's

221

222

223

224

225

226

227

228 claims that mechanical or physiological explanations of patellar morphology have "no scientific merit". Haxton (1944) also criticised De Vriese for focusing on relative length of bones; his own "patellar index" based on relative width found no correlation with animal speed or size, but he inferred that the patella confers functional advantages in knee extension. There has been little examination of these questions in a modern comparative, rigorously statistical or biomechanical context since these studies. A notable exception is a study of the distal femur and patellar groove in bovid mammals, indicating increased mechanical advantage of the knee in larger species (Kappelman 1988).

The occurrence of an ossified patella in the knee joint is not universal among tetrapods (Fig. 3). A

230

231

232

233

234

235

236

237

238

239

240 bony patella is absent in extinct early Tetrapoda and crown clade Lissamphibia (Dye 1987; Haines 1942; Herzmark 1938; Vickaryous \& Olson 2007), all non-avian dinosaurs, Crocodylia, and Testudines (turtles), and all other extinct tetrapods. Hebling et al. (2014; their fig. 3A) illustrate what seems to be a patella formed of soft tissue in the bullfrog Lithobates catesbeianus. That fascinating observation needs a more comprehensive examination across Anura and Urodela to test if a soft tissue "patelloid" is ancestral for Lissamphibia or smaller clades. In contrast, an ossified patella is present in many or most Squamata (lizards and kin) with limbs (Camp 1923; Carrano 2000; De Vriese 1909; Dye 1987; Dye 2003; Gauthier et al. 2012; Haines 1940; Haines 1942; Hutchinson 2002; Hutchinson 2004; Jerez \& Tarazona 2009; Maisano 2002a; Regnault et al. 2016; Vickaryous \& Olson 2007). Patellar status (used throughout our study to refer to presence/absence of ossification in adults) is unknown for the (mostly extinct) Rhynchocephalia (sister group to Squamata), although a patella is at least sometimes present in the tuatara Sphenodon - the only extant rhynchocephalian (Regnault et al. 2016). An apparent sesamoid bone was noted in the knee joint region of a specimen of Macrocnemus, a mid-Triassic $(\sim 235$ Mya) reptile, which may be the earliest identified occurrence of a patella in any animal group (Rieppel 1989), although this structure may have been a different sesamoid bone or ossicle. There have been anecdotal accounts of fibrocartilaginous or "fibrovesicular" patelloids in some reptiles such as turtles and crocodiles (Haines 1940; Haines 1942; Pearson \& Davin 1921a; Pearson \& Davin 1921b), but these are not well-explored. Thus, although such fibrous tissues seem to be excellent candidates for intermediate evolutionary character states between "absence of ossified patella (normal extensor tendon)" and "presence of ossified patella", empirical grounding for this transformational sequence within Sauropsida is weak.

252 No patella has been observed in early, stem-group birds throughout the Jurassic and Cretaceous periods, except in the well-documented Cretaceous Hesperornithes, diving birds with vestigial wings and an extremely large and unusually shaped patella, resembling that in some extant diving birds (Lucas 1903; Marsh 1875; Martin 1984; Martin \& Tate 1976; Shufeldt 1884; Thompson 1890). A patella is found in some Cenozoic fossil bird specimens, most notably archaic penguins, and commonly among many crown clade birds (Dye 1987; Dye 2003; Hutchinson 2001; Hutchinson 2002; Ksepka et al. 2012; Shufeldt 1884; Vickaryous \& Olson 2007; Walsh \& Suarez 2006). Our recent study (Regnault et al., 2014) inferred that a patella was probably ancestrally present in the common ancestor of Hesperornithes and living birds over 70 Mya. However, the bony patella was lost (and in some cases replaced by fatty cartilaginous tissue) in some large 
262 flightless birds such as emus, cassowaries and the extinct moa, yet unexpectedly is present as a

263 double ossification in the knee joints of ostriches (Chadwick et al. 2014).

264 An osseous patella is generally found in two of the three crown groups of Mammalia: Eutheria 265 (Fig. 3) and Monotremata (see Fig. 4A-D), but not in most Metatheria (see Fig. 4E, F) (Dye

266 1987,2003; Vickaryous \& Olson 2007). This raises the question whether this patella represents 267 independent, convergent evolutionary origins in the Eutheria and Monotremata, or an ancestral

268 origin for all three groups, with loss of the ossified patella amongst most Metatheria. To address

269 this question, we conducted phylogenetic character mapping with Mesquite software (Maddison

270 \& Maddison 2017) that reconstructed patellar evolution in Mammalia. Using likelihood methods,

271 we also traced the most likely pattern of evolution over existing phylogenies, and considered

272 alternate proposed topologies to test how they affected our reconstructions. Based on the

273 predicted evolutionary patterns and individual morphologies, we propose suggestions as to the

274 lifestyle of particular taxa, and consider where general correlations between lifestyle and patellar

275 presence/absence might exist (or not).

276 Mottershead called the patella "that prince among sesamoids" but questioned whether it is "not 277 typical of its kind" (Mottershead 1988). But is there even a "typical" patella (bony or otherwise)? 278 Our synthesis of key data from morphology and function to phylogeny, development and genetics 279 allows us to evaluate just how "typical" any patella is, even for a mammalian patella.

\section{MATERIALS AND METHODS}

281 Our methods followed standard phylogenetic character mapping (i.e. evolutionary

282 reconstructions) methods in comparative biology (e.g. Baum \& Smith 2013; Cunningham et al. 1998; Huelsenbeck et al. 2003); with details as follow. We surveyed the literature and additional specimens (Fig. 4; Table S1 and Figs. S1-S3) and coded the patella as absent (score =0), fibrocartilaginous (i.e. "patelloid"; score $=1$ ), or ossified (score $=2$ ) for each taxon in our analysis, with "?" denoting an ambiguous character coding. We did not code the "suprapatella" here as there is substantial confusion over its homology. We used two phylogenetic optimization methods in Mesquite software (Maddison \& Maddison 2017) to reconstruct possible evolutionary polarity of the patella in the clade Mammaliamorpha (with a focus on Mammaliaformes), as follows. First, for broad reconstruction across Tetrapoda, we used a phylogeny based on Gauthier et al. (1988) and Shedlock and Edwards (2009), with average branch lengths they derived from several studies. Some aspects of the phylogeny remain controversial, such as the position of Testudines (turtles; Hedges 2012). Reconstruction was performed using Mesquite's parsimony algorithm and unordered character states and results are illustrated in Figure 3. As this analysis only involved major clades and not any stem lineages, it was intended as purely illustrative of general patterns and the current state of knowledge, given that patellar evolution across Tetrapoda had not been analyzed phylogenetically before.

We adopted composite phylogenetic trees for our study taxa (Archibald 1998; Beck 2012; Bi et al. 2014; Cardillo et al. 2004; Forasiepi et al. 2006; Gatesy et al. 2013; Goloboff et al. 2009;

300 Kielan-Jaworowska et al. 2004; Luo et al. 2003; Luo 2007a; Luo et al. 2002; Luo 2007b; May301 Collado et al. 2015; Meredith et al. 2009; Meredith et al. 2011; Mitchell et al. 2014; O'Leary et al. 302 2013; O'Leary \& Gatesy 2008; dos Reis et al. 2012; Rose 2006; Sánchez-Villagra et al. 2007;

303 Song et al. 2012; Spaulding et al. 2009; Springer et al. 2003; Springer et al. 2007; Springer et al. 304 2009; Thewissen 1990; Thewissen et al. 2007; Wible et al. 2007; Zack et al. 2005). As defined by 
305 several authors, the clade Mammaliaformes includes crown group Mammalia plus closely related

306 extinct stem-mammals such as the iconic Morganucodon and the more recently discovered

307 Sinoconodon, and is characterised by diagnostic features involving the teeth, jaw and inner ear

308 (Kielan-Jaworowska et al. 2004; Rose 2006). Extant mammals (crown group Mammalia) include

309 three main clades: Placentalia, Marsupialia and Monotremata. Placentalia lie within the Eutheria;

310 Marsupialia lie within the Metatheria, and Monotremata lie within the Australosphenida, all of

311 which diverged during the Mesozoic, pre-dating the K-Pg extinction event 66 Mya.

312 The overall phylogeny used for Mesozoic mammals (Fig. 5) was based on the topology of Bi et

313 al. (2014); their main figure 4 and extended data figure 9. However, we chose to show

314 Henkelotherium branching prior to Vincelestes following (Luo 2007) because their relationship

315 with Theria was less well-resolved in Bi et al. (2014). Approximate divergence times for key

316 clades were taken from Bi et al. (2014)'s figure 4. Divergence of Vincelestes, Henkelotherium and

317 Akidolestes came from Luo (2007). The remaining undated divergences and branch lengths ere

318 estimated using data from the Paleobiology database (fossilworks.org), accounting for the date

319 ranges of fossil taxa.

320 The topology of the metatherian tree was based on several sources that are all fairly congruent

321 with one another. Sinodelphys was least nested, as in Luo et al. (2003), followed by Asiatherium,

322 Pucadelphys + Mayulestes, Herpetotherium, and crown Marsupalia as shown by Sánchez-

323 Villagra et al. (2007) (also by Beck 2012; Luo et al. 2003). Sparassodonta were sister to crown

324 Marsupialia (Babot et al. 2002; Forasiepi et al. 2006; Suarez et al. 2016). The topology and

325 divergence dates of crown Marsupialia were from Mitchell (2014). Divergence dates of

326 Sinodelphys, Asiatherium, and of Pucadelphys from Mayulestes were from Luo et al. (2003).

327 Dates within Sparassodonta were taken from Forasiepi (2009). The remaining undated nodes

328 were estimated, so that the interbranch lengths between dated nodes was approximately equal.

329 The topology of basal eutherians used Hu et al.'s (2010), with Juramaia polytomous with Eomaia 330 and crown Placentalia as in Luo et al. (2011), which also brought the basal eutherian node back to $331 \sim 160$ mya. Alternative placement of Eomaia as a stem therian (as in O'Leary et al. 2013) was also

332 explored as a supplementary analysis. The branch order of the main crown Placentalia clades

333 (Xenarthra, Afrotheria, Euarchontoglires, and Laurasiatheria), as well as the placement of many

334 of the extant and fossil groups, came from O'Leary et al. (2013). Divergence dates of extant taxa

335 were estimated from the Timetree database Timetree.org (Hedges et al. 2006). Divergence dates

336 of fossil taxa were from O'Leary et al. (2013) or estimated from fossil dates from the

337 Paleobiology database as above.

338 Exceptions and expansions to the topology of O'Leary et al. (2013) were as follows: (1) The 339 placement of Pantodonta and Taeniodonta is ambiguous, but both groups were suggested to be 340 derived from the cimolestids (McKenna \& Bell 1997). Here we placed these groups as stem 341 eutherians (Rook \& Hunter 2014). (2) Within primates, we placed Omomys, Teilhardina, 342 Archicebus, Notharctus and Plesiadapis (Ni et al. 2013). (3) Within Glires, Nonanomalurus was 343 classified with Anomaluroidea, diverging from the group containing Sciuridae (Marivaux et al. 344 2016), and adopting a divergence date of 60MYA. Apatemyids like Apatemys chardini may be 345 basal members of Euarchontoglires, with weak support for a sister-group relationship with Glires 346 (Silcox et al. 2010). (4) The topology within Carnivora was based on Flynn et al. (2005). (5) The 347 detailed topology within Cetartiodactyla followed Spaulding et al. (2009). Maiacetus was placed 348 alongside Rodhocetus and Artiocetus (within Protocetiidae). Gervachoerus was placed tentatively 349 alongside Diacodexis (as it is classified within Dichobunoidea); its actual placement is unclear. 
350

351

352

353

354

355

356

357

358

359

360

361

362

363

364

365

366

367

368

369

370

371

372

373

374

375

376

377

378

379

380

381

382

383

384

385

386

387

388

389

390

391

392

Paratylopus, Merychyus and Protoreodon were placed near to Camelus, within Camelidamorpha, but again their exact relationships are unclear. (6) The detailed topology of Perissodactyla followed Holbrook \& Lapergola (2011). Notoungulata and Eoauchenia (Litopterna) were placed sister to Perissodactyla (Welker et al. 2015). Following recent analyses (e.g. Cooper et al. 2014), we placed Phenacodontidae and Desmostylia as stem perissodactyls. (7) The position of Dinocerata is controversial. Here we placed Dinocerata within Laurasiatheria, close to Perissodactyla and Cetartiodactyla (Burger 2015), until more data on the placement of this group becomes available. (8) The detailed topology within Chiroptera followed Simmons et al. (2008).

Our analysis involved numerous challenges and caveats. Many anatomical studies of extant or extinct species omit any mention of the patella, leaving its provenance in these taxa as uncertain. Interpretation of patellar status is especially challenging in fossils due to the rarity of finds with extensive, articulated postcranial material, the potential occurrence of other small non-patellar bones in the knee joint, and the uncertain age of the animal at time of death versus the developmental timing of sesamoid ossification (usually unknown; often relatively late in ontogeny). For the present analysis, statements in the primary literature regarding patellar status were generally accepted at face value except when superseded by more recent observations. From some publications with high quality photographs, patellar status was tentatively interpreted even if not discussed in the original text. In some cases, patellar status was confirmed by direct observation (e.g. Fig. 4; Figs. S1-S3; Table S1). Drawings found in secondary citations were mostly not been taken as definitive evidence, as we noticed examples of discrepancies between primary references and such drawings found in review articles or even textbooks, which may simply assume patellar status in mammals. Also, many mammalian groups are found over long temporal and geological spans, thus we were cautious about using the presence of a patella in one or a few individual extant or fossil specimens to infer presence throughout the group, although in some cases there was clearly enough conservatism within a clade to score it for all members.

An important knee structure related to the patella is the femoral patellar or intercondylar sulcus (groove) (Norell \& Clarke 2001; Polly 2007). This sulcus is anatomically associated with a true patella (Figs. 1,4) in terms of its direct role in guiding the patellar sesamoid and tendon's path of movement during leg flexion/extension, and in mediolaterally confining the patellar tendon, which may enhance osteogenic stresses favouring the formation of a patella (Sarin \& Carter 2000b; Wren et al. 2000). In the absence of an observed patella in fossil specimens, this sulcus at the distal end of the femur is sometimes treated as evidence of a patella even in the absence of the observed bone itself. We deemed this conclusion to be unwarranted. For example, the evolution of a patellar sulcus in early pygostylian birds substantially predated the evolution of an ossified patella in later ornithurine birds; moreover the sulcus was retained in some avian taxa that lost the patella (Clarke \& Norell 2002; Hutchinson 2002; Livezey \& Zusi 2006; Regnault et al. 2014). In contrast, a prominent sulcus is absent in many Squamata despite the presence of a patella (S.R. and J.R.H., pers. obs.). Together these observations indicate that these two anatomical features are not obligatorily coupled, so reliance on the observed presence of an ossified patella in fossil specimens was warranted. Nonetheless, at least among mammals the complete absence of a femoral patellar sulcus might be indicative of the absence of an ossified patella (Chester et al. 2012).

\section{RESULTS AND DISCUSSION}


393 Our overall evolutionary reconstruction of the patella for Mesozoic mammals is shown in Fig. 5,

394 for Metatheria/Marsupialia in Fig. 6, and for Cenozoic Eutheria/Placentalia in Fig. 7, with details

395 for specific taxa in Table S1 and alternative phylogenetic analyses in Figs. S4 and S5. Here we

396 sequentially summarize and discuss our findings for five subgroups of Mammaliamorpha

397 (especially Mammaliaformes): (1) Mesozoic pre-therians and stem-therians; (2) Mesozoic

398 Metatheria and Eutheria; (3) Cenozoic Monotremata; (4) Cenozoic Metatheria, and (5) Cenozoic

399 Eutheria. We then conclude with a general synthesis of our study's insights (as well as

400 uncertainties) and a consideration of how available and emerging data on developmental genetics

401 of the patella might help shed light on the "evo-devo" of the patella, augmenting the phylogenetic

402 and anatomical insights that this study focuses on.

403

404

405

406

407

408

409

410

411

412

413

414

415

416

417

418

419

420

421

422

423

424

425

426

427

428

429

430

431

432

433

434

435

436

\section{Mesozoic pre-therian and stem-therian mammals}

The earliest mammals as widely construed include Sinoconodon, the Morganucodonta and Docodonta. These were mostly small, probably insectivorous animals, that appear to have lacked a patella, although it is unclear whether the known specimens contain sufficient postcranial material or are from verified adults, to allow for definitive conclusions. The absence of a clear patella in two stunningly preserved docodonts (the scansorial [climbing-adapted] Agilodocodon and fossorial [digging-adapted] Docofossor) lends credence to the conclusion that it was generally absent in early mammaliaforms (Luo et al. 2015b; Meng et al. 2015). There is convincingly strong evidence of absence of a bony patella in earlier pre-mammals in lineages dating from the divergence of Synapsida and Sauropsida/Reptilia ( $\sim 320$ Mya), including the early "pelycosaurs", therapsids and cynodonts (Kemp 2005).

Australosphenida, the clade containing and thus ancestral to extant Monotremata, diverged from other mammals extremely early, possibly in the mid-Jurassic (Kielan-Jaworowska et al. 2004). There is little postcranial material for any extinct members of this lineage however, and no hindlimbs (Kemp 2005). The patella in crown clade monotremes is discussed below.

Fruitafossor, from the late Jurassic (150 Mya), diverged after the Australosphenida (Luo \& Wible 2005). Its relationship to other early mammals is complicated by its mixture of characters in the molar teeth, middle ear and elsewhere. Fruitafossor is described as lacking a patella, and it is proposed to have had a fossorial lifestyle.

The Eutriconodonta were found abundantly across the world from the middle Jurassic to early Cretaceous periods (Kielan-Jaworowska et al. 2004). Among eutriconodonts, a poorly developed patellar groove on the distal femur is found but an ossified patella is absent.

The Allotheria were an extremely successful and widely dispersed group of mammals, among which the best understood are the multituberculates (Kielan-Jaworowska et al. 2004; Wilson et al. 2012). Generally Allotheria are found from the late Triassic to the Eocene; thus this group spanned the heyday of the non-avian dinosaurs and survived the K-Pg extinction (KielanJaworowska et al. 2004). Multituberculates were predominantly small animals, either herbivorous or omnivorous (Kielan-Jaworowska et al. 2004). A patella is noted for the nearly complete multituberculate Ptilodus, a proposed scansorial animal from the early Cenozoic. A patella is also present in the Cretaceous multituberculate Chulsanbaatar. It is unclear whether a patella is typical of all members of the multituberculate group and is under-reported due to lack of hindlimb material for most group members, or whether it occurs only among selected species, although the former seems more plausible. A patella is not reported, however, for the early Jurassic basal Rugosodon, a proposed multituberculate specimen with one relatively intact knee 
437 joint (Yuan et al. 2013), so it is conceivable that an ossified patella evolved later within the 438 Allotheria (Fig. 5).

439 Specimens of the diverse group "Haramiyida" are mostly restricted to cranial material, and the 440 relationship of this ancient group to other Allotheria and Mammaliaformes has been controversial 441 (Butler 2000; Kielan-Jaworowska et al. 2004; Rose 2006). However, several recently described 442 more complete haramiyid specimens from the Jurassic with at least one preserved knee joint lack 443 a patella (Bi et al. 2014; Zheng et al. 2013; Zhou et al. 2013). These new specimens have been 444 interpreted to support an Allotheria clade including a paraphyletic "Haramiyida" (but a valid 445 clade Euharamyida including many "haramiyid" taxa) and Multituberculata (Fig. 5), although 446 new analyses of a key specimen of Haramiyavia concluded that the haramiyids and multituberculates were not closely related (Luo et al. 2015a). The inclusion of the "Euharamiyida" in Allotheria pushes the divergence date of the group significantly earlier into the late Triassic, whereas multituberculates themselves appear only in the middle to late Jurassic. Final resolution of this controversy will undoubtedly require additional fossil material.

Symmetrodonta were a group of diverse, small mammals widely distributed in time from the late Triassic to the late Cretaceous (Kielan-Jaworowska et al. 2004). In the subgroup of spalacotheroids, a patella is reported for one fairly complete specimen (Zhangheotherium) but not for another (Akidolestes) (Chen \& Luo 2012; Luo \& Ji 2005) (these two specimens are coded oppositely in character matrices in some subsequent publications (Bi et al. 2014; Zhou et al. 2013), probably in error); a patella seems absent in Maotherium.

457 Eupantotheria was a diverse group found commonly from the mid-Jurassic to the early 458 Cretaceous (Kielan-Jaworowska et al. 2004). The patella is reported as absent in both an early 459 European specimen (Henkelotherium, late Jurassic) and a later South American specimen 460 (Vincelestes, early Cretaceous) (Fig. 5). The large group of dryolestid Eupantotheria possibly 461 survived past the K-Pg boundary, have an unknown patellar status.

462 The tribotherians were the earliest-diverging group to share key molar features with the therians. 463 However, no postcranial specimens have been reported; thus nothing is known of their patellar 464 morphology (Kielan-Jaworowska et al. 2004).

465 The single specimen of Juramaia from the Jurassic ( $\sim 60$ Mya) unfortunately lacks hindlimb 466 material; therefore its patellar status is unknown. Based on its forelimb, Juramaia is proposed to have been scansorial or possibly arboreal (Luo et al. 2011). The later specimen of Eomaia from the early Cretaceous includes all limb elements, and is described with a patella (Ji et al. 2002).

469 Based on limb and foot features, Eomaia was probably scansorial or arboreal. In the original publication, Eomaia was described as the earliest eutherian mammal (Fig. 5), however a more recent and much more extensive analysis confidently placed Eomaia prior to the

472

473 eutherian/metatherian divergence (O'Leary et al. 2013) and thus at least as a stem member of the clade Theria (see Fig. S4). Eomaia (and presumably Juramaia) postdate the divergence of the Symmetrodonta, but their positions relative to the Eupantotheria remain to be determined, as does any close relationship between these two key taxa. Lacking a better alternative, here we refer to these taxa as "Theria", and in Fig. 5 vs. Fig. S4, consider the consequences of Eomaia's phylogenetic position on our conclusions.

478 In surveying the available data mapped onto our composite phylogeny (Figs. 5, S4), it becomes 479 evident that an ossified patella evolved multiple times (at least four) along the mammalian stem 
480

481

482

483

484

485

486

487

488

489

490

491

492

493

494

495

496

497

498

499

500

501

502

503

504

505

506

507

508

509

510

511

512

513

514

515

516

517

518

519

520

521

522

523

524

lineages during the Mesozoic era, whether using parsimony or maximum likelihood optimisation methods: at some highly uncertain time in the long mammalian lineage that led to Monotremata, in multituberculates/Allotheria, in Zhangheotherium or a direct ancestor, and likely twice (or between one to three times, depending on the placement of Eomaia; see Figs. 5 and S4) in the clade containing Eomaia and Theria (Metatheria and Eutheria). This result remained the same if the Euharamiyida were not included with multituberculates but pre-dated crown Mammalia, as suggested by some recent studies (e.g. Luo et al. 2015a).

\section{Mesozoic Metatheria and Eutheria}

The two major extant mammalian groups, the Metatheria and Eutheria (together forming the clade Theria), diverged as early as the Jurassic (Fig. 5). The earliest fossil identified as stem metatherian, Sinodelphys, dates from the early Cretaceous of China (125 Mya, approximately contemporary to Eomaia), and lacks a patella (Luo et al. 2003). A patella also seems absent in the less complete Cretaceous stem metatherian Asiatherium (Szalay \& Trofimov 1996).

The earliest known occurrences of the patella in definitive stem eutherians (Figs. 5,7) were in the late Cretaceous Ukhaatherium (Horovitz 2003), a relatively unspecialized form, and in Zalambdalestes (Wible et al. 2005), a more specialized taxon sometimes described as resembling later lagomorphs (Rose 2006). Patellar status at the crown group node for Theria (plus Eomaia) remains ambiguous (Figs. 5,6,S4), as we consider below.

\section{Cenozoic Monotremata}

The origins of the Monotremata (egg-laying mammals) are poorly understood. They are considered extant members of the clade Australosphenida (the alternative term Prototheria has been superseded), and hence with early roots in the Mesozoic. Molecular studies based on the sequenced genome of the platypus corroborate the long held interpretation that the monotremes diverged prior to the metatherian/eutherian split, consistent with proposed fossil-based phylogenies (Warren et al. 2008). Unfortunately, there are almost no reported hindlimb specimens of any extinct monotreme (including probable early monotreme fossils found in South America; (Musser 2003)), with the exception of the Pleistocene Zaglossus (echidna) from Australia and New Guinea (which may be the same as the extant species of that name). Unfortunately, although fossil Zaglossus hindlimb elements exist, including an articulated knee, neither presence nor absence of the patella has been reported (Murray 1984). The extant monotremes, the platypus (Ornithorhynchus anatinus) and the echidnas (Tachyglossidae, two genera Zaglossus and Tachyglossus; four known species) all have substantial patellae (see Fig. 4A, B, C, D) (Herzmark 1938; Rowe 1988). It is unclear when the two extant monotreme genera diverged, although a date early in the Cretaceous has been proposed (Rowe et al. 2008), and it is impossible for now to date the appearance of the patella in the monotreme lineage. Regardless, an ossified patella is homologous for this crown clade (Fig. 5), and alternative phylogenetic topologies did not change the general pattern of patellar evolution (Fig. S4).

\section{Cenozoic Metatheria}

All extant Metatheria are within the subgroup of Marsupialia, however non-marsupials did exist earlier during the Cenozoic. As documented in the pioneering study of sesamoids in Marsupialia by Reese et al. (2001), an ossified patella seems to be absent in the great majority of extant marsupial species, both from Australia and the Americas (Flores 2009; Herzmark 1938; Holladay et al. 1990; Reese et al. 2001; Rose 2006; Rowe 1988), including the sole surviving North American marsupial, the opossum Didelphis virginiana (Fig. 4E, F). Many marsupials have other sesamoid bones in the knee region (e.g. the parafibula, lateral sesamoid, or "sesamoid bone of 
525 Vesalli"; Fig. 1), as well as a fibrocartilaginous "patelloid", which may to some degree serve the 526 mechanical function of a bony patella (Reese et al. 2001). However, the mechanics of a fibrous or 527 bony patella remain essentially unstudied (to our knowledge) in non-placental mammals, so this 528 is simply speculation. Studies have claimed some association between reduction of the patella in 529 many marsupials and locomotor style or ecology (Holladay et al. 1990; Reese et al. 2001), but 530 these deserve testing with more detailed sampling across phylogeny and ontogeny.

531 Nonetheless, an ossified patella is found in a small number of extant marsupial species among 532 otherwise divergent clades, both from Australia: at least several Peramelidae or bandicoots, and 533 the two marsupial mole species of Notoryctes); and from South America: Tarsipes, a honey 534 possum; and several, and possibly all, Caenolestidae or shrew opossums (see Fig. 6: note collapse 535 of several large clades in terms of total number of species, in which no species have been shown 536 to possess a bony patella; Table S1).

537 Possibly uniquely among crown clade marsupials, bandicoots also possess a chorioallantois fused 538 to the uterine epithelium (i.e. a true placenta) (Freyer et al. 2003; Padykula \& Taylor 1976), 539 which combined with an osseous patella led to the initial suggestion that they might actually be 540 eutherians (Reese et al. 2001). However, more recent molecular and fossil-based phylogenetic 541 studies provide no support for that hypothesis of eutherian bandicoots (Asher et al. 2004; 542 Meredith et al. 2008b; Sanchez-Villagra et al. 2007; Westerman et al. 2012). Bandicoots clearly 543 are metatherians, and their chorioallantois is thus a convergently evolved trait rather than 544 plesiomorphic. It remains to be determined whether an ossified patella is present in all or only 545 some bandicoots, as so far it is only reported in the Peramelinae of dry or temperature forests of 546 Australia, not yet in the Peroryctinae of tropical rainforests of New Guinea, or the more distantly related bilbies (Groves \& Flannery 1990; Meredith et al. 2008a; Westerman et al. 2012). Similarly, a comprehensive study of the Caenolestidae remains to be performed, much as a more thorough study of the major marsupial clade Diprotodontia (wombats, kangaroos and kin) is needed.

Not surprisingly given the absence of a bony patella in most extant marsupials, any evidence of a patella is absent in the early Cenozoic Metatheria Pucadelphys, Mayulestes, and the later Herpetotherium. Unexpectedly, a bony patella is reliably reported in the Borhyaenoidea, an 554 unusual group of dog-like carnivorous South American marsupials found from the Palaeocene through the Miocene (Argot 2002; Argot 2003a; Argot 2003b; Argot 2003c; Argot 2004; Argot \& Babot 2011; de Muizon et al. 1997). Patellar status in some members of Borhyaenoidea (e.g. Borhyaena itself and Lycopsis (Argot 2004)), and in the more inclusive group Sparassodonta, is

558 uncertain due to the incomplete state of specimens. Szalay and Sargis (2001) noted other 559 enigmatic fossil patellae from the Palaeocene of Brazil that they assigned to Metatheria, but the 560 phylogenetic relationships of those fragmentary remains are unclear and no patellae were shown.

561 However, no ossified patella is reported in extant or recent carnivorous marsupials such as

562 Thylacinus.

563 Two related, pernicious problems remain for interpreting the evolution of the patella in 564 Metatheria that may have ramifications for all of Mammalia/Mammaliaformes. First, Szalay and 565 Sargis (2001:pp.164-5) reported the presence of an ossified patella in older individuals of

566 Didelphis virginiana in their study of an ontogenetic series from this species. They stated (p.165) 567 "In older individuals there is occasionally an elongated and small sesamoid ossification within 568 the tendon of the quadriceps femoris where it crosses the knee joint when the knee is flexed." 569 However, this observation was not documented with illustrations or photographs (especially 
570 tissue histology or X-rays) and hence remains a tantalizing anecdote. Similarly, Owen (1866) 571 commented that some marsupials had no ossifications in their patellar tendon but others had 572 "only a few irregular specks of ossification" and a "distinct but small bony patella in the 573 Macropus Bennettii." In contrast, Reese et al. (2001) and Holladay et al. (1990) respectively 574 sampled 61 specimens ( $\sim 39$ adults) from 30 species of marsupials and 3 macropodid specimens 575 (of unknown maturity), documenting no ossified patellae except as noted in bandicoots, and their 576 studies used clear methods for identifying ossified tissues. It remains possible that patellar 577 ossification occurs variably in older individuals among Metatheria, which would help explain its 578 patchy description in known taxa.

579 If the latter situation is the case (i.e. the literature is unclear about patellar ossification in 580 marsupials because they have more inherent variability), then it relates to a second problem, a 581 cladistic one of character coding and transformational homology (sensu Brower \& Schawaroch 582 (1996); Pinna (1991)). Should character states of the patella in metatherians, or even all mammals 583 and their kin, be coded as an ordered transformational series such as absent (0), fibrocartilaginous 584 (1) or ossified (2), or as an unordered series (i.e. should evolutionary steps be required to go from 585 0-1-2 as 2 steps, or unordered allowing 0-2 transformations as 1 step)? We chose the unordered 586 character option by default for all crown group mammals, but where relevant explain how an 587 ordered option changed (or did not change) our results. An endochondral ossification of the bony 588 patella is certain, but a fibrocartilaginous or otherwise soft tissue composition of the patella 589 (coded as state 1) in adults is not unambiguously the necessary (i.e. ordered) evolutionary 590 precursor character state to state 2 (ossified patella in adults). The solution to both of these 591 problems lies in more developmental data for the patella (bony and otherwise) in diverse 592 mammalian species, in addition to more scrutiny of the adult morphology in extant and fossil 593 Mammalia (especially Metatheria).

594 As noted briefly in the Introduction, many marsupials have a primarily fibrocartilaginous 595 patelloid in place of an ossified patella and some other mammals may have a "suprapatella". The 596 developmental and evolutionary relationships of these structures remain somewhat unclear, 597 particularly as some marsupials with an ossified patella (e.g. bandicoots) also possess a patelloid 598 (Reese et al., 2001), suggesting that the patelloid is not developmentally equivalent to the patella 599 in marsupials (Vickaryous \& Olson 2007). If so, this would indicate independent evolutionary

600 histories of these two structures. Further work is required to clarify the relationships of the 601 patelloid and suprapatella at least in extant taxa, before definitive evolutionary trajectories can be 602 inferred. We reiterate that, just because a patella-like structure is not ossified, that does not mean 603 it is a distinct organ deserving a new name and different homology as a phylogenetic character604 although it may be a distinct state of the character "patella". However, either of these two 605 possibilities needs careful testing particularly for Metatheria.

606 A non-osseous patelloid/suprapatella is also found in several closely related modern placental 607 clades that lie far from the base of Eutheria (Fig. 7), suggesting that these represent independent 608 acquisitions. We have not attempted to explicitly reconstruct the evolution of the patelloid in 609 Eutheria. Lewis (1958) and Broome and Houghton (1989) speculated that the mammalian 610 patelloid might be a precursor to the tibial epiphysis (Broome \& Houghton 1989; Lewis 1958) -611 a so-called "traction epiphysis" (Vickaryous \& Olson 2007). Yet considering that the patelloid 612 evolved after the tibial tuberosity (and proximal tibial epiphysis as well as distal femoral 613 epiphysis; Carter et al. 1998) of mammals, not before it, and lies proximal rather than distal to the 614 patella, we reject this hypothesis. More study of the evolution of mammaliaform long bone 615 epiphyses, however, is warranted to strongly and more generally test for associations between 
616 any epiphyses and sesamoids. Furthermore, this same phylogenetic evidence indicates that the 617 patelloid in Euarchontoglires, some Carnivora and bandicoots is not ancestrally associated with 618 leaping or other behaviours (e.g. Jungers et al., 1980). As Walji \& Fasana (1983) caution, the 619 ancestral mechanical environment of the patelloid/suprapatella and its roles in different 620 behaviours remain unclear, although it does seem to be associated with knee hyperflexion like a typical fibrocartilaginous "wrap-around" tendon (e.g. Ralphs et al. 1991; Alexander \& Dimery, 1985).

623 Our unordered parsimony reconstruction (Fig. 6) indicated that an ossified patella was absent in 624 the ancestor of Metatheria, then evolved in the ancestor of Sparassodonta and Marsupialia. The bony patella may have been lost in the basal lineages of Marsupialia (reconstructed state here was equally parsimonious between an ossified and fibrocartilaginous patella), with subsequent reacquisition in certain groups (Tarsipedidae, and possibly Notoryctidae and Thylacomyidae + Peramelidae, and Tarsipedidae) (Fig. 6). Ordered parsimony reconstruction resulted in subtle differences; making some nodes less ambiguous (i.e. state 1 [patelloid present] within basal Marsupialia) and others more ambiguous (such as the ancestor of Sparassodonta and Marsupialia, which became equally parsimonious between states 1 and 2). In contrast, maximum likelihood reconstruction indicated a single origin of the osseous patella in Metatheria (Fig. 6), with reduction to a fibrocartilage patelloid (in Didelphidae and the clade containing

634

635 Pseudocheiridae+Vombatidae) and re-acquisition of a bony patella (in Tarsipedidae) marginally more likely than multiple instances of ossified patella evolution. Because presence of a patelloid has not been clearly excluded in some extant marsupials (e.g. Petauridae, Acrobatidae) and is unlikely to be fossilised, its reconstruction must be treated carefully. Finally, alternative placement of Microbiotheriidae did not drastically alter our evolutionary reconstructions (Fig. S5), aside from making a single origin of the ossified patella slightly more likely. Overall, we caution that inferences about the evolutionary history of the patella in Metatheria must remain tentative until further data become available.

\section{5. Cenozoic Eutheria}

643 The Placentalia include all extant Eutheria as well as some fossil stem taxa (Fig. 7). Although there is some fossil evidence for placentals pre-dating the K-Pg event (Archibald et al. 2011), as well as substantial molecular dating consistent with an older placental radiation, the timing of the placental radiation remains highly controversial. However, our major conclusions about patellar evolution in placentals are not dependent on how this controversy is ultimately resolved, as a recent large-scale phylogenetic analysis convincingly established the presence of an osseous patella as a derived character state in the ancestral placental irrespective of its true date of divergence (O'Leary et al. 2013).

Fossil evidence supports the presence of the bony patella in essentially all Cenozoic placental groups (Fig. 7; also see Table S1 and Figs. S1-S4, with citations therein). Specimens with sufficient hindlimb material to make a determination of patellar status are rare in the early

654 Cenozoic Palaeogene period ( 66-23 Mya), but Palaeocene groups in which an ossified patella 655 has been reported include the Taeniodonta (small to medium sized fossorial animals), Pantodonta (early herbivores), Palaeanodonta (small, possible insectivores; perhaps related to pangolins), "Condylarthra" (a diverse assemblage of putatively related taxa, probably polyphyletic, including both herbivores and carnivores, many of which may be stem members of subclades within the

659 placental crown group), and the Plesiadapiformes, a sister group to crown clade primates (and 660 possibly members of the clade Primates as well) (Bloch \& Boyer 2007; Silcox 2007). In general, 
661 the evolutionary relationships between Palaeocene taxa and more recent placentals remain 662 enigmatic.

663 Eocene placentals include examples whose close relationships to modern groups are well

664 accepted. Among Eocene groups (Fig. 7, Table S1), an osseous patella has been reported in older,

665 extinct groups such as "Condylarthra", Creodonta (carnivores), Mesonychia

666 (carnivorous/omnivorous artiodactyls or cetartiodactyls), Dinocerata (large hippo/equid-like

667 herbivores), Brontotheriidae (large rhino-like herbivores), and Notoungulata (diverse South

668 American hoofed herbivores; probably related to Afrotheria) (O'Leary et al. 2013), as well as in

669 extinct species (in parentheses, see Table S1 for citations) recognized as stem members of several

670 extant groups: Glires (Rhombomylus), Perissodactyla (Propalaotherium), early Sirenia retaining

671 hindlimbs (Pesoziren, Protosiren), Proboscidea (Numidotherium, Moeritherium, Barytherium),

672 Rodentia (the horse-sized Pseudotomus, Paramys), Pholidota (Eomanis), Artiodactyla

673 (Gervachoerus), early Cetacea retaining hindlimbs (Maiacetus) and Chiroptera (Icaronycteris,

674 Tachypteron). A bony patella is also reported for several Eocene primates, including the lemur-

675 like Notharctidae (Northarctus) and the tarsier-like Omomys and Archicebus, in addition to the

676 enigmatic primate Darwinius.

677 Despite an extensive literature search, we found no reports attesting to the presence of an osseous

678 patella in certain widely cited Paleocene and Eocene species, including: Protungulatum,

679 frequently cited as the earliest true placental; Miacis, Vulpavus, Viverravus and Didymictis, which

680 were stem Carnivora (Gregory 1920; Heinrich \& Houde 2006; Heinrich \& Rose 1995; Heinrich

681 \& Rose 1997; Samuels et al. 2013); Pakicetus, a fully quadrupedal early cetacean (though

682 sometimes reconstructed with a bony patella as in Fig. 7 and Fig. S1 M, N) (Thewissen et al.

683 2001); Leptictis, possibly related to crown clade lagomorphs (Rose 1999); Sinopa, a creodont

684 (Matthew 1906); and the early primates Adapis, Leptadapis, Teilhardina, and Cantius (Dagosto

685 1983; Gebo et al. 2012a; Gebo et al. 2012b; Rose \& Walker 1985; Schlosser 1887; Szalay et al.

686 1975). There is no reason to expect that a bony patella is missing in these species. These absences

687 are more likely due to incompleteness of the fossil record and/or literature descriptions and

688 images. Moreover, the massive collections of Eocene specimens from the Messel and Green

689 River lagerstätten in Germany and Wyoming have not yet been fully described (Grande 1984;

690 Schaal \& Ziegler 1992). There are many examples of an ossified patella in specimens from extant

691 placental groups across the more recent Miocene, Oligocene, Pliocene and Pleistocene, but a

692 comprehensive search of the literature for those geologic epochs was deemed redundant for our

693 major conclusions.

694 Based on fossi1/morphological evidence plus extensive genomic DNA sequencing, there is a

695 consensus that crown clade placentals can be historically and geographically defined by four

696 major groups: Xenarthra, Afrotheria, Euarchontoglires (further divided into Euarchonta; featuring

697 Primates; and Glires) and Laurasiatheria (Rose 2006). These in turn may be resolved, with

698 somewhat less consensus, into 19 crown clade "orders" (Fig. 7) (O'Leary et al. 2013). In two of

699 these orders, the afrotherian clade Sirenia and the cetacean branch of (Cet)artiodactyla

700 (laurasiatherian clade), extant members have extensively reduced or absent hindlimbs and thus

701 lack skeletal knee structures, including an osseous patella. In contrast, the bony patella is retained

702 among the aquatic seals and sea lions in Carnivora, although unlike Sirenia and Cetacea these

703 animals still display some terrestrial habits and thus presumably still employ the gearing

704 mechanism that the patella is involved in at the knee. An ossified patella is documented as present

705 in at least some members of all other 17 placental "orders" (e.g. Figs. 4G,H,7,S1-S3; Table S1) 
706 (de Panafieu \& Gries 2007; De Vriese 1909; Dye 1987; Herzmark 1938; Lessertisseur \& Saban

707 1867; Rose 2006).

708 The evolution of the Cetacea presents an interesting scenario regarding patellar evolution (Fig. 7).

709 Cetaceans evolved from a common ancestor with other (cet)artiodactyls (Spaulding et al. 2009;

710 Thewissen et al. 2007). Early artiodactyls (including cetaceans), such as Diacodexis and

711 Indohyus, shared morphological similarities with both extant groups of Cetacea (toothed and

712 baleen whales) and yet retained an osseous patella (Rose 1982; Thewissen et al. 2007), much as

713 stem Sirenia did (Domning 2001; Zalmout 2008). Patellar status in Pakicetus, a presumptive

714 early cetacean with full hindlimbs, remains uncertain based on the primary literature, but

715 presence is likely considering the presence of a bony patella in its closest relatives. Rodhocetus

716 and Ambulocetus, probably semi-aquatic early cetaceans, still had large hindlimbs and ossified

717 patellae (Madar et al. 2002). The pelvis and hindlimbs are greatly reduced in the later cetaceans

718 Dorudon and Basilosaurus, but a bony patella is still present in these animals (Gingerich et al.

719 1990; Uhen 2004). It is not clear exactly when the patella was lost altogether in later cetaceans

720 with increasingly reduced hindlimbs.

721 Bats present another interesting case of patellar evolution (Fig. 7; Table S1). An osseous patella is 722 generally present in bats (Pearson \& Davin 1921b). A bony patella is also reported in a well-

723 preserved hindlimb of an early Eocene bat, Icaronycteris, of intermediate form but proposed to be

724 a microchiropteran (Jepsen 1966). However, in studies of multiple genera of modern bats

725 including members from both of the major subgroups Megachiroptera and Microchiroptera

726 (which is possibly paraphyletic), a bony patella was noted as absent in four species of the

727 megachiropteran Pteropus (flying foxes of various sizes), and a few individual species of

728 Cephalotes, Epomophorus and Vespertilio (De Vriese 1909; Lessertisseur \& Saban 1867; Smith

729 et al. 1995). No obvious lifestyle distinction was noted for the Pteropus genus as compared to

730 many other bats, hence the loss of the ossified patella in members of this particular subgroup (and

731 others) remains mysterious. In general, bat hindlimbs are highly derived, adapted to hanging and

732 pulling rather than pushing. A few bats such as the vampire bats are actively quadrupedal (Adams

733 \& Thibault 2000; Riskin \& Hermanson 2005). Bat hindlimbs are articulated in abduction, so that

734 the knee faces dorsally; as in the original ancestral orientation for Tetrapoda (Fig. 2) (Neuweiler

735 2000; Schutt \& Simmons 2006). There remains a need for a comprehensive study of the patella in

736 bats (Smith et al. (1995) only studied 31 specimens of 13 species), but this is challenging due to

737 the existence of $>900$ extant bat species (Jones et al. 2002). The microstructure of the "patelloid"

738 in Pteropus is generally similar to that in many marsupials (e.g. deep layer of fibrocartilage;

739 superficial layer of dense connective tissue contiguous with the quadriceps/patellar tendon)

740 (Smith et al. 1995). This also raises the question of whether the patella only ossifies later in

741 adulthood in Pteropus, rather than not ossifying at all.

742 General evolutionary patterns and ambiguities

743 Considering the above distributions of patellar presence/absence in Mammalia (Figs. 5-7; Figs.

744 S4,S5) and our data matrix (Table S1), the simplest interpretation of the evolutionary record of

745 the patella in mammals (by parsimony and maximum likelihood mapping of presence/absence) is

746 that this structure arose (i.e. ossified) independently at least four times (but possibly up to six),

747 mostly during the Mesozoic era: 1, in Australosphenida ancestral to modern monotremes; 2, in

748 Multituberculata (later than Rugosodon); 3, in Symmetrodonta (specifically in Spalacotheroidea

749 that were ancestral to Zhangheotherium but not Akidolestes); 4-6, in early Theria (including

750 Eutheria, Metatheria, Eomaia and related stem groups; depending on topology between one and

751 three times in this clade). Conceivably, a single common patelloid precursor may pre-date the 
752 origins of the bony patellae, or the bony patella may have arisen fewer times and undergone loss

753 (and re-gain) in some lineages, similarly to the pattern in Metatheria. Each of these scenarios

754 remain difficult to test purely with fossil evidence, however, due to the typical lack of

755 preservation of cartilaginous or fibrous structures.

756 Once the bony patella evolved in Eutheria, it was highly conservative in its presence (Fig. 7).

757 There are very few examples of fossil or extant Eutheria in which the hindlimb remains intact but

758 the patella is unossified in adults (e.g. Pteropus). A caveat is that many fossil specimens are not

759 sufficiently complete for a definitive rejection of patellar ossification in those taxa. Still, the

760 evolutionary stability of the osseous patella in Eutheria stands in contrast to its general variability

761 across mammals, and suggests some conserved functional requirement and/or ontogenetic

762 mechanism that remains to be determined.

763 Although an ossified patella is absent in the majority of Metatheria, it is reported in several

764 groups (Figs. 6, S5). This likely represents some loss and regain(s) of the early metatherian bony

765 patella. Importantly, in this case the presence of a fibrocartilaginous "patelloid" in most

766 marsupials shows a clear evolutionary polarity from an ossified patella to a non-ossified

767 patelloid, and back again in the case of the secondary gain of ossification, in each case within

768 Metatheria (Reese et al. 2001). This "patella to patelloid" transition suggests the reverse may also

769 be possible - that a soft tissue patelloid may represent the evolutionary precursor to an ossified

770 patella - but it has yet to be clearly documented. There is no obvious lifestyle or biomechanical

771 correlate among all four groups of osseous patella-bearing Metatheria: the notoryctid moles are

772 underground burrowers, and bandicoots may dig for insects, but Tarsipes is a nectar feeder and

773 the borhyaenoids/sparassodonts were largely terrestrial carnivores. In contrast, other Australasian

774 carnivorous marsupials including the recently extinct thylacine, and the extant quoll, numbat and

775 Tasmanian devil are not reported to have a bony patella.

776 The large size of the patella in the monotreme platypus might be related to its aquatic (and partly

777 fossorial) lifestyle. The other monotremes, the echidnas, also burrow and the long-beaked species

778 (Zaglossus) lives in underground dens-- further suggesting an association between fossorial

779 habits and the presence or enlargement of a bony patella in Monotremata, as well as in some

780 fossil Mammaliaformes (multituberculates?) but curiously not in other fossorial stem taxa (e.g.

781 the docodont Docofossor). Reduction of the patella in the Cetacea and Sirenia is not intrinsically

782 correlated with their aquatic lifestyle, but with the reduction of the hindlimbs as part of their

783 particular adaptations. Elsewhere in groups with aquatic adaptations, for example in various

784 diving birds, an unusually large patella is found. It seems premature to weave detailed scenarios

785 around the high degree of convergent evolution of the osseous patella in mammals until the

786 biomechanical function and genomic control of the patella are better understood, and improved

787 phylogenetic sampling improves resolution of when it evolved in particular lineages.

788 Patellar developmental genetics

789 Molecular phylogenomics provides a potential independent or synergistic approach to resolving

790 issues of patellar evolution. If specific genomic sequence signatures could be associated with

791 patellar status, then comparison of the genomes of the various extant but widely separated groups

792 with a bony patella might indicate whether these represent convergence events or a common

793 ancestral event (i.e. identified via shared evolutionarily transmitted genetic markers required for

794 patellar development). For example, it has recently been shown that the ability to taste sweet

795 carbohydrates in hummingbirds represents a trait convergence. Hummingbirds diverged from the

796 insectivorous swifts, in which the sweet taste receptor is inactivated by mutations in the receptor 
797 coding gene. In hummingbirds, the ability to taste sweet has been re-acquired, apparently through

798 molecular adaptation of the umami receptor to detect sweet molecules (Baldwin et al. 2014). It

799 would be helpful to understand the (developmental) genetics of the patella as a step toward the

800 identification of such sequence signatures. Developmental genetic studies in two mammals,

801 humans and mice, have identified genes required for correct patellar specification. The known

802 functions of some of these genes are informative regarding their requirements.

803 There are currently approximately 12 human genetic disorders with identified molecular bases

804 that regularly include abnormal, reduced or absent patellae (hypoplasia or aplasia) as an

805 important aspect of the phenotype (reviewed by Bongers et al. (2005), see also Warman et al.

806 (2011) and Table S2 for details). There are also several genes whose genetics in mice indicates

807 relevance to patellar development at least in rodents. A detailed discussion of all these syndromes

808 and genes is beyond the scope of this study. However, the known patella-related genes can be

809 broadly organized according to three major developmental processes: limb specification and

810 pattern formation (transcription factors such as $L M X 1 B, T B X 4$, PITX1 and mouse Hoxaaccdd-11,

$811 S O X 11$, and signalling factor $W N T 7 A)$; bone development, biochemistry and regulation (GDF5,

$812 C H R N G, S L C 26 A 2, C O L 9 A 2, A K T 1)$; and genes involved in DNA replication and chromatin

813 (ORC1, ORC4, ORC6, CDT1, CDC6, GMNN, CDC45, RECQL4, KAT6B, ESCO2). Of these, the

814 genes of replication and chromatin are the most unexpected, and potentially of the most interest

815 for evolutionary studies. Patellar ossification may be dependent on the timing of DNA replication

816 in particular cells, or else may be affected by aberrant gene regulation resulting from mutations in

817 replication and chromatin factors. In either case, the target genes mis-regulated in these

818 syndromes, if they can be identified, may provide useful evolutionary markers to distinguish

819 convergent from homologous patellar status.

820 Developmental studies in mouse or chick embryos, sometimes with induced paralysis, document

821 the additional importance of local environmental factors in patellar ontogenesis (Hosseini \&

822 Hogg 1991; Mikic et al. 2000; Nowlan et al. 2010a; Nowlan et al. 2010b; Osborne et al. 2002;

823 Rot-Nikcevic et al. 2006). Similarly, embryonic development and hindlimb activity in the case of

824 particular marsupials may be important in understanding the diversity of patellar states in this

825 group. A better understanding of these environmental processes will also be helpful to disentangle

826 genomic versus epigenomic regulation of patellar development, and hence evolution.

828 How "the mammalian patella" evolved

829 The widespread, repeated evolution of the bony patella across evolution argues for an important

830 role in locomotor biomechanics. In animals lacking an ossified patella (e.g. Lissamphibia,

831 Testudines, Crocodylia; as well as many extinct lineages of tetrapods), the consequences of this

832 ancestral absence for hindlimb function remain mostly unstudied. This mystery is striking, in

833 particular, within Mammalia where most marsupials lack an ossified patella, as did numerous

834 fossil stem-mammals, despite seeming to share common ecological niches and the associated

835 locomotor requirements. This sporadic occurrence in marsupials and stem mammals contrasts

836 with its near universality and evolutionary stability in the Eutheria as noted above.

837 The exact number of independent origins of a bony patella among mammals remains unclear, but

838 we have estimated at least four convergent episodes inside Mammaliaformes, and several

839 instances of patellar "loss" (with apparent re-gain in some marsupials). The pattern of acquisition 
840 and loss will require revisiting as new fossil material is discovered, as our evolutionary 841 reconstructions are dependent on single specimens for many ancient taxa. Moreover, patellar 842 status has not been verified for all $>5,000$ eutherian and $>330$ metatherian species (Wilson \& 843 Reeder 2005), so it is possible that additional placental species (other than the fully aquatic 844 forms) may be found lacking, or marsupials having, a bony patella. A recent evolutionary study

845 documented many apparently independent evolutionary origins of the caecal appendix in 846 mammals; thus the convergent evolution of unusual anatomical structures like the osseous patella 847 has precedent (Smith et al. 2013). Similarly, blue coloration among tarantula spiders apparently 848 involved at least eight independent evolutionary acquisitions, among different microscopic 849 anatomical structures affecting spectral reflectance and hence general external colour (Hsiung et 850 al. 2015). A better understanding of the genomic signatures required for development of such 851 novel structures should be very helpful to deconstruct the observed complex patterns of 852 evolution, distinguishing between convergent evolution (homoplasy) and shared inheritance 853 (synapomorphy/homology).

854 Given that the patella evolved, and was also lost, multiple times in mammals and other Tetrapoda 855 (Fig. 3), one thing is clear. Much as we have referred to "the patella" throughout this study, there 856 is no such thing - perhaps not even a single "mammalian patella". The story of patellar evolution 857 is one of many (bony) patellae; a story of diverse evolutionary origins as well as forms, functions, 858 ontogenies and perhaps even diverse underlying genetics. Mottershead (1988) wondered if the 859 patella is "not typical of its kind" for a sesamoid bone (Mottershead 1988). Yet even patellae are 860 not necessarily typical for patellae, let alone other sesamoids-- there are double or fatty patellae 861 in some birds (Regnault et al. 2014), proximal suprapatellae and/or fibrocartilaginous patelloids

862 in many marsupials, no ossified (or even other forms of) patellae in many species, and even 863 amongst those animals that have patellae, there are numerous shapes and sizes of patellae (Figs.

864 4,S1-S3), suggesting still-unappreciated lifestyle constraints in patellar (and knee joint)

865 mechanics.

866 While we have provisionally used the terms "patelloid" and "suprapatella" for non-ossified 867 tissues near where the patella is or might be found, the validity of these terms needs further 868 inspection in a broader context. Certainly, patellae exist in non-ossified forms in younger animals 869 before endochondral ossification completes, and where such ossification does not initiate at all 870 during ontogeny it may be best to apply the term "patella" to such tissues rather than invoke new 871 terms for the same organ that simply underwent different tissue development; as above, a case of 872 divergent character state transformation rather than distinct characters (i.e. new organs). This is 873 not simply a semantic issue as the implications for evolutionary novelty, adaptation and "evo874 devo" of patella-like structures will depend on the decisions made about homology of these traits 875 in organisms, and how those decisions are communicated by the choice of anatomical 876 terminology.

877 Future prospects

878 Our discussion of patellar evolution in Mammalia has identified several areas where key 879 questions remain unresolved, in addition to uncertainties about the amount of 880 convergence/parallel evolution in origins of the osseous patella and about specific roles of (and 881 interactions between) genetic/developmental factors in bony patellar formation/loss. Considering 882 that mechanical loads are known to play an important role in the development of sesamoid bones 883 (in particular in early ontogeny), studies linking these loads to genetic/developmental control as 884 well as broad evolutionary patterns could prove very insightful, especially in explaining the 885 seemingly large amount of patellar homoplasy in mammalian evolution. Mammals may be less 
886 sensitive (i.e. more genetically assimilated (e.g. Vickaryous \& Olson 2007)) than birds in terms

887 of the relative influence of mechanical loads on bone (including sesamoid) ontogeny (Nowlan et

888 al. 2010b) -- this idea deserves better testing as insight into load-based influences improves.

889 Furthermore, indications that some bones within an organism may be more responsive to their

890 loading regime (Nowlan et al. 2010a) may be of great relevance to interpreting patellar biology

891 and evolution, but at present strong inferences cannot be drawn about how variable the patella's

892 responsiveness to mechanics is within or among organisms. There is clearly much room for

893 further study of the patellae of mammals and other tetrapods, and here we have noted directions

894 in which these might most beneficially be directed. 
896 Tremendous thanks are due to the many investigators who have generously given their time and 897 energy to educating MES in the fine points of hindlimb anatomy and tetrapod evolution. Special 898 thanks to John Wible, Zhe-Xi Luo, Maureen O'Leary, Daniel Gebo, Emmanuel Gheerbrant, Jin 899 Meng, Pascal Tassy, Cyrille Delmer, Salamet Mahboubi, Xijun Ni and Bruce Shockey for help 900 with information on early mammals, Bonnie Smith, Norberto Giannini and Bill Schutt for help 901 with bats, Mike Archer, Vera Weisbecker, Robin Beck, Tom Grant and Kurt Galbreath for help 902 with monotremes, Guillermo Rougier, Jose Bonaparte, Eric Sargis, Anna Gillespie, Analia 903 Forasiepi and Natalie Warburton for help with marsupials, Cheri Deal, David Skidmore, Judith 904 Hall, Philippe Campeau and Les Biesecker for information on patellar genetics, Virginie Millien 905 and Anthony Howell for access to and discussion of materials at the McGill University Redpath 906 Museum of Natural History in Montreal, and Michel Gosselin for access to and documentation of 907 materials at the Canadian Museum of Nature in Ottawa. We thank Matthew Lowe (curator, 908 University Museum of Zoology, Cambridge, UK) for access to osteological specimens of 909 mammals. We also thank numerous reviewers of earlier versions of the manuscript for many 910 valuable suggestions. 
912 Adams RA, and Thibault KM. 2000. Ontogeny and evolution of the hindlimb and calcar:

913

914

915

916

917

918

919

920

921

922

923

924

925

926

927

928

929

930

931

932

933

934

935

936

937

938

939

940

941

942

943

944

945

946

947

948

949

950

951

952

953

954

955

956

957

958 assessing phylogenetic trends. In: Adams RA, and Pedersen SC, eds. Ontogeny, functional ecology, and evolution of bats. Cambridge: Cambridge University Press.

Aglietti P, and Menchetti PPM. 1995. Biomechanics of the patellofemoral joint. In: Scuderi GR, ed. The Patella. New York City: Springer.

Ahlberg PE, Clack JA, and Blom H. 2005. The axial skeleton of the Devonian tetrapod Ichthyostega. Nature 437:137-140.

Alexander RM, and Dimery NJ. 1985. The significance of sesamoids and retro-articular processes for the mechanics of joints. Journal of Zoology 205:357-371.

Andrews SM, and Westoll TS. 1970. The postcranial skeleton of Eusthenopteron foordi whiteaves. Transactions of the Royal Society of Edinburgh 68:207-329.

Archibald JD. 1998. Archaic ungulates ("Condylarthra"). In: Janis CM, Scott KM, and Jacobs LL, eds. Evolution of Tertiary Mammals of North America. Cambridge: Cambridge University Press.

Archibald JD, Zhang Y, Harper T, and Cifelli R. 2011. Protungulatum, confirmed Cretaceous occurrence of an otherwise Paleocene Eutherian (Placental?) mammal. Journal of Mammalian Evolution 18:153-161.

Argot C. 2002. Functional-adaptive analysis of the hindlimb anatomy of extant marsupials and the paleobiology of the Paleocene marsupials Mayulestes ferox and Pucadelphys andinus. J Morphol 253:76-108.

Argot C. 2003a. Functional-adaptive anatomy of the axial skeleton of some extant marsupials and the paleobiology of the paleocene marsupials Mayulestes ferox and Pucadelphys andinus. J Morphol 255:279-300.

Argot C. 2003b. Functional adaptations of the postcranial skeleton of two Miocene borhyaenoids (Mammalia, Metatheria), Borhyaena and Prothylacinus, from South America. Palaeontology 46:1213-1267.

Argot C. 2003c. Postcranial functional adaptations in the South American Miocene borhyaenoids (Mammalia, Metatheria): Cladosictis, Pseudonotictis and Sipalocyon. Alcheringa: An Australasian Journal of Palaeontology 27:303-356.

Argot C. 2004. Functional-adaptive analysis of the postcranial skeleton of a Laventan Borhyaenoid, Lycopsis longirostris (Marsupialia, Mammalia). Journal of Vertebrate Paleontology 24:689-708.

Argot C, and Babot J. 2011. Postcranial morphology, functional adapations and palaeobiology of Callistoe vincei, a predaceous metatherian from the Eocene of Salta, northwestern Argentina. Palaeontology 54:447-480.

Asher RJ, Horovitz I, and Sanchez-Villagra MR. 2004. First combined cladistic analysis of marsupial mammal interrelationships. Mol Phylogenet Evol 33:240-250.

Babot MJ, Powell JE, and de Muizon C. 2002. Callistoe vincei, a new Proborhyaenidae (Borhyaenoidea, Metatheria, Mammalia) from the Early Eocene of Argentina. Geobios 35:615-629.

Baldwin MW, Toda Y, Nakagita T, O'Connell MJ, Klasing KC, Misaka T, Edwards SV, and Liberles SD. 2014. Sensory biology. Evolution of sweet taste perception in hummingbirds by transformation of the ancestral umami receptor. Science 345:929-933.

Barnett CH, and Lewis OJ. 1958. The evolution of some traction epiphyses in birds and mammals. J Anat 92:593-601.

Barton RS, Ostrowski ML, Anderson TD, Ilahi OA, and Heggeness MH. 2007. Intraosseous innervation of the human patella: a histologic study. Am J Sports Med 35:307-311. 
959

960

961

962

963

964

965

966

967

968

969

970

971

972

973

974

975

976

977

978

979

980

981

982

983

984

985

986

987

988

989

990

991

992

993

994

995

996

997

998

999

1000

1001

1002

1003

1004

1005

1006

1007

Baum DA, and Smith SD. 2013. Tree Thinking: An Introduction to Phylogenetic Biology. Roberts \& Company Publishers.

Beck RM. 2012. An 'ameridelphian' marsupial from the early Eocene of Australia supports a complex model of Southern Hemisphere marsupial biogeography. Naturwissenschaften 99:715-729.

Benjamin M, Toumi H, Ralphs JR, Bydder G, Best TM, and Milz S. 2006. Where tendons and ligaments meet bone: attachment sites ('entheses') in relation to exercise and/or mechanical load. $J$ Anat 208:471-490.

Bertollo N, Pelletier MH, and Walsh WR. 2012. Simulation of patella alta and the implications for in vitro patellar tracking in the ovine stifle joint. J Orthop Res 30:1789-1797.

Bertollo N, Pelletier MH, and Walsh WR. 2013. Relationship between patellar tendon shortening and in vitro kinematics in the ovine stifle joint. Proc Inst Mech Eng H 227:438-447.

Bi S, Wang Y, Guan J, Sheng X, and Meng J. 2014. Three new Jurassic euharamiyidan species reinforce early divergence of mammals. Nature 514:579-584.

Bland YS, and Ashhurst DE. 1997. Fetal and postnatal development of the patella, patellar tendon and suprapatella in the rabbit; changes in the distribution of the fibrillar collagens. J Anat 190:327-342.

Bloch JI, and Boyer DM. 2007. New skeletons of Paleocene-Eocene Plesiadapiformes: A diversity of arboreal positional behaviors in early primates. In: Ravoso MJ, and Dagosto M, eds. Primate Origins: Adaptations and Evolution. New York: Springer, 535-581.

Boisvert CA. 2005. The pelvic fin and girdle of Panderichthys and the origin of tetrapod locomotion. Nature 438:1145-1147.

Broome GH, and Houghton GR. 1989. A congenital abnormality of the tibial tuberosity representing the evolution of traction epiphyses. J Anat 165:275-278.

Brower AV, and Schawaroch V. 1996. Three steps of homology assessment. Cladistics 12:265272.

Burger B. 2015. The systematic position of the saber-toothed and horned giants of the Eocene: the Uintatheres (Order Dinocerata) Society of Vertebrate Paleontology Annual Meeting. Dallas, Texas, USA.

Butler DL, Kay MD, and Stouffer DC. 1986. Comparison of material properties in fascicle-bone units from human patellar tendon and knee ligaments. J Biomech 19:425-432.

Butler PM. 2000. Review of the early Allotherian mammals. Acta Palaeontologica Polonica 45:317-342.

Camp CL. 1923. Classification of the lizards. Bulletin of the American Museum of Natural History 48:289-480.

Carrano M. 2000. Homoplasy and the evolution of dinosaur locomotion. Paleobiology 26:489512.

Carter DR, Mikić B and Padian K. 1998. Epigenetic mechanical factors in the evolution of long bone epiphyses. Zool J Linn Soc 123:163-178.

Chadwick KP, Regnault S, Allen V, and Hutchinson JR. 2014. Three-dimensional anatomy of the ostrich (Struthio camelus) knee joint. PeerJ 2:e706.

Chen M, and Luo Z. 2012. Postcranial skeleton of the Cretaceous mammal Akidolestes cifellii and its locomotor adaptations. Journal of Mammalian Evolution 20:159-189.

Chester SGB, Sargis EJ, Szalay FS, Archibald JD, and Averianov AO. 2012. Therian femora from the Late Cretaceous of Uzbekistan. Acta Palaeontologica Polonica 57:53-64.

Clark J, and Stechschulte DJ, Jr. 1998. The interface between bone and tendon at an insertion site: a study of the quadriceps tendon insertion. $J$ Anat 192:605-616.

Clarke JA, and Norell MA. 2002. The morphology and phylogenetic position of Apsaravis ukhaana from the late Cretaceous of Mongolia. American Museum Novitates 3387:1-47. 
1008 Cooper LN, Seiffert ER, Clementz M, Madar SI, Bajpai S, Hussain ST, and Thewissen JGM.

1009

1010

1011

1012

1013

1014

1015

1016

1017

1018

1019

1020

1021

1022

1023

1024

1025

1026

1027

1028

1029

1030

1031

1032

1033

1034

1035

1036

1037

1038

1039

1040

1041

1042

1043

1044

1045

1046

1047

1048

1049

1050

1051

1052

1053

1054

1055

1056
2014. Anthracobunids from the middle Eocene of India and Pakistan are stem perissodactyls. PLoS One 9:e109232.

Cunningham CW, Omland KE, and Oakley TH. 1998. Reconstructing ancestral character states: a critical reappraisal. Trends in Ecology \& Evolution 13:361-366.

Daeschler EB, Shubin NH, and Jenkins FA, Jr. 2006. A Devonian tetrapod-like fish and the evolution of the tetrapod body plan. Nature 440:757-763.

Dagosto M. 1983. Postcranium of Adapis parisiensis and Leptadapis magnus (Adapiformes, Primates). Folia Primatological 41:49-101.

de Muizon C, Cifelli RL, and Paz RC. 1997. The origin of the dog-like borhyaenoid marsupials of South America. Nature 389:486-489.

de Panafieu J-B, and Gries P. 2007. Evolution. New York: Seven Stories Press.

De Vriese B. 1909. Recherches sur l' anatomie comparée de la rotule. Bulletin of the Royal Academy of Medicine of Belgium.

Domning DP. 2001. The earliest known fully quadrupedal sirenian. Nature 413:625-627.

dos Reis M, Inoue J, Hasegawa M, Asher RJ, Donoghue PC, and Yang Z. 2012. Phylogenomic datasets provide both precision and accuracy in estimating the timescale of placental mammal phylogeny. Proc Biol Sci 279:3491-3500.

Dye SF. 1987. An evolutionary perspective of the knee. J Bone Joint Surg Am 69:976-983.

Dye SF. 2003. Functional morphologic features of the human knee: an evolutionary perspective. Clin Orthop Relat Res:19-24.

Eckstein F, Muller-Gerbl M, and Putz R. 1992. Distribution of subchondral bone density and cartilage thickness in the human patella. J Anat 180:425-433.

Editors. 1992. The patella. Lancet 339:341.

Evans EJ, Benjamin M, and Pemberton DJ. 1991. Variations in the amount of calcified tissue at the attachments of the quadriceps tendon and patellar ligament in man. J Anat 174:145151.

Eyal S, Blitz E, Shwartz Y, Akiyama H, Ronen S, and Zelzer E. 2015. On the development of the patella. Development.

Farnum CE. 2007. Postnatal growth of fins and limbs through endochondral ossification. In: Hall BK, ed. Fins into Limbs. Chicago: University of Chicago.

Fellows RA, Hill NA, Gill HS, MacIntyre NJ, Harrison MM, Ellis RE, and Wilson DR. 2005. Magnetic resonance imaging for in vivo assessment of three-dimensional patellar tracking. J Biomech 38:1643-1652.

Flores DA. 2009. Phylogenetic analyses of postcranial skeletal morphology in Didelphid marsupials. Bulletin of the American Museum of Natural History 320:1-81.

Flynn JJ, Finarelli JA, Zehr S, Hsu J, Nedbal MA, and Bininda-Emonds O. 2005. Molecular phylogeny of the Carnivora (Mammalia): Assessing the impact of increased sampling on resolving enigmatic relationships. Syst Biol 54:317-337.

Forasiepi AM. 2009. Osteology of Arctodictis sinclairi (Mammalia, Metatheria, Sparassodonta) and phylogeny of Cenozoic metatherian carnivores from South America. Monografias del Museo Argentino de Ciencias Naturales 6:1-174.

Forasiepi AM, Sánchez-Villagra MR, Goin FJ, Takai M, Shigehara N, and Kay RF. 2006. A new species of Hathliacynidae (Metatheria, Sparassodonta) from the middle Miocene of Quebrada Honda, Bolivia. Journal of Vertebrate Paleontology 26:670-684.

Fox AJ, Wanivenhaus F, and Rodeo SA. 2012. The basic science of the patella: structure, composition, and function. J Knee Surg 25:127-141.

Freyer C, Zeller U, and Renfree MB. 2003. The marsupial placenta: a phylogenetic analysis. $J$ Exp Zool A Comp Exp Biol 299:59-77. 
1057 Gatesy J, Geisler JH, Chang J, Buell C, Berta A, Meredith RW, Springer MS, and McGowen MR.

1058

1059

1060

1061

1062

1063

1064

1065

1066

1067

1068

1069

1070

1071

1072

1073

1074

1075

1076

1077

1078

1079

1080

1081

1082

1083

1084

1085

1086

1087

1088

1089

1090

1091

1092

1093

1094

1095

1096

1097

1098

1099

1100

1101

1102

1103
2013. A phylogenetic blueprint for a modern whale. Mol Phylogenet Evol 66:479-506.

Gauthier JA, Kearney M, Maisano JA, Rieppel O, and Behlke ADB. 2012. Assembling the squamate tree of life : perspectives from the phenotype and the fossil record. Bulletin of the Peabody Museum of Natural History 53:3-308.

Gebo DL, Dagosto M, Ni X, and Beard KC. 2012a. Species diversity and postcranial anatomy of Eocene primates from Shanghuang, China. Evol Anthropol 21:224-238.

Gebo DL, Smith T, and Dagosto M. 2012b. New postcranial elements for the earliest Eocene fossil primate Teilhardina belgica. J Hum Evol 63:205-218.

Gingerich PD, Smith BH, and Simons EL. 1990. Hind limbs of Eocene Basilosaurus: evidence of feet in whales. Science 249:154-157.

Giori NJ, Beaupre GS, and Carter DR. 1993. Cellular shape and pressure may mediate mechanical control of tissue composition in tendons. J Orthop Res 11:581-591.

Goloboff PA, Catalano SA, Mirande JM, Szumik CA, Arias JA, Kallersjo M, and Farris JS. 2009. Phylogenetic analysis of 73,060 taxa corroborates major eukaryotic groups. Cladistics 25:211-230.

Grande L. 1984. Paleontology of the Green River Formation, with a review of the fish fauna. Wyoming: Geological Survey of Wyoming.

Gregory WK. 1920. On the structure and relations of Notharctus, an American Eocene primate. Memoirs of the American Museum of Natural History. New York: American Museum of Natural History. p 1-243.

Griffith CJ, Laprade RF, Coobs BR, and Olson EJ. 2007. Anatomy and biomechanics of the posterolateral aspect of the canine knee. J Orthop Res 25:1231-1242.

Groves CP, and Flannery T. 1990. Revision of the families and genera of bandicoots. In: Seebeck JH, Brown PR, Wallis RL, and Kemper CM, eds. Bandicoots and Bilbies. Chipping Norton: Surrey Beatty and Sons.

Guernsey DL, Matsuoka M, Jiang H, Evans S, Macgillivray C, Nightingale M, Perry S, Ferguson M, LeBlanc M, Paquette J, Patry L, Rideout AL, Thomas A, Orr A, McMaster CR, Michaud JL, Deal C, Langlois S, Superneau DW, Parkash S, Ludman M, Skidmore DL, and Samuels ME. 2010. Mutations in origin recognition complex gene ORC4 cause Meier-Gorlin syndrome. Nat Genet 43:360-364.

Haines RW. 1940. Note on the independence of sesamoid and epiphysial centres of ossification. $J$ Anat 75:101-105.

Haines RW. 1942. The tetrapod knee joint. J Anat 76:270-301.

Haines RW. 1974. Epiphyses and Sesamoids. In: Gans C, ed. Biology of the Reptilia. New York: Academic Press, 81-115.

Hargrave-Thomas EJ, Thambyah A, McGlashan SR, and Broom ND. 2013. The bovine patella as a model of early osteoarthritis. J Anat 223:651-664.

Harris HA. 1937. The foetal growth of the sheep. J Anat 71:516-527.

Haxton H. 1944. The patellar index in mammals. J Anat 78:106-107.

Hebling A, Esquisatto MAM, Aro AA and Gomes L. 2014. Morphological modifications of knee articular cartilage in bullfrogs (Lithobates catesbeianus)(Anura: Ranidae) during postmetamorphic maturation. Zoomorphology 133:245-256.

Hedges SB, Dudley J, and Kumar S. 2006. TimeTree: a public knowledge-base of divergence times among organisms. Bioinformatics 22:2971-2972.

Heegaard J, Leyvraz PF, Curnier A, Rakotomanana L, and Huiskes R. 1995. The biomechanics of the human patella during passive knee flexion. J Biomech 28:1265-1279. 
1104 Heinrich RE, and Houde P. 2006. Postcranial anatomy of Viverravus (Mammalia, Carnivora) and

1105

1106

1107

1108

1109

1110

1111

1112

1113

1114

1115

1116

1117

1118

1119

1120

1121

1122

1123

1124

1125

1126

1127

1128

1129

1130

1131

1132

1133

1134

1135

1136

1137

1138

1139

1140

1141

1142

1143

1144

1145

1146

1147

1148

1149

1150

1151

implications for substrate use in basal Carnivora. Journal of Vertebrate Paleontology 26:422-435.

Heinrich RE, and Rose KD. 1995. Partial skeleton of the primitive Carnivoran Miacis petilus from the early Eocene of Wyoming. Journal of Mammalogy 76:148-162.

Heinrich RE, and Rose KD. 1997. Postcranial morphology and locomotor behaviour of two early Eocene Miacoid carnivorans, Vulpavus and Didymictis. Palaeontology 40:297-305.

Herzmark MH. 1938. Evolution of the knee joint. Journal of Bone and Joint Surgery 200:77-84.

Hildebrand M. 1998. Analysis of Vertebrate Structure: Wiley.

Holbrook LT, and Lapergola J. 2011. A new genus of perissodactyl (Mammalia) from the Bridgerian of Wyoming, with comments on basal perissodactyl phylogeny. Journal of Vertebrate Paleontology 31:895-901.

Holladay SD, Smith BJ, Smallwood JE, and Hudson LC. 1990. Absence of an osseous patella and other observations in Macropodidae stifle. Anat Rec 226:112-114.

Horovitz I. 2003. Postcranial Skeleton of Ukhaatherium nessovi (Eutheria, Mammalia) from the Late Cretaceous of Mongolia. Journal of Vertebrate Paleontology 23:857-868.

Hosseini A, and Hogg DA. 1991. The effects of paralysis on skeletal development in the chick embryo. I. General effects. $J$ Anat 177:159-168.

Howale DS, and Patel ZK. 2013. Hypothesis: morphology and development of the patella. International Journal of Scientific and Research Publications 3:1-5.

Hsiung BK, Deheyn DD, Shawkey MD, and Blackledge TA. 2015. Blue reflectance in tarantulas is evolutionarily conserved despite nanostructural diversity. Sci Adv 1:e1500709.

$\mathrm{Hu}$ Y, Meng J, Li C, and Wang Y. 2010. New basal eutherian mammal from the Early Cretaceous Jehol biota, Liaoning, China. Proceedings of the Royal Society B: Biological Sciences 277:229-236.

Huelsenbeck JP, Nielsen R, and Bollback JP. 2003. Stochastic mapping of morphological characters. Systematic Biology 52:131-158.

Hutchinson JR. 2001. The evolution of femoral osteology and soft tissues on the line to extant birds (Neornithes). Zoological Journal of the Linnean Society 131:169-197.

Hutchinson JR. 2002. The evolution of hindlimb tendons and muscles on the line to crown-group birds. Comp Biochem Physiol A Mol Integr Physiol 133:1051-1086.

Hutchinson JR. 2004. Biomechanical modeling and sensitivity analysis of bipedal running ability. II. Extinct taxa. J Morphol 262:441-461.

Jepsen GL. 1966. Early Eocene bat from Wyoming. Science 154:1333-1339.

Jerez A, and Tarazona OA. 2009. Appendicular skeleton in Bachia bicolor (Squamata: Gymnophthalmidae): osteology, limb reduction and postnatal skeletal ontogeny. Acta Zoologica 90:42-50.

Ji Q, Luo ZX, Yuan CX, Wible JR, Zhang JP, and Georgi JA. 2002. The earliest known eutherian mammal. Nature 416:816-822.

Jones KE, Purvis A, MacLarnon A, Bininda-Emonds OR, and Simmons NB. 2002. A phylogenetic supertree of the bats (Mammalia: Chiroptera). Biol Rev Camb Philos Soc 77:223-259.

Jungers WL, Jouffroy FK, and Stern JT, Jr. 1980. Gross structure and function of the quadriceps femoris in Lemur fulvus: an analysis based on telemetered electromyography. J Morphol 164:287-299.

Kaiser S, Cornely D, Golder W, Garner M, Waibl H, and Brunnberg L. 2001. Magnetic resonance measurements of the deviation of the angle of force generated by contraction of the quadriceps muscle in dogs with congenital patellar luxation. Vet Surg 30:552-558.

PeerJ reviewing PDF | (2016:11:14426:1:1:NEW 15 Feb 2017) 
1152 Kappelman J. 1988. Morphology and locomotor adaptations of the bovid femur in relation to

1153

1154

1155

1156

1157

1158

1159

1160

1161

1162

1163

1164

1165

1166

1167

1168

1169

1170

1171

1172

1173

1174

1175

1176

1177

1178

1179

1180

1181

1182

1183

1184

1185

1186

1187

1188

1189

1190

1191

1192

1193

1194

1195

1196

1197

1198

1199 habitat. J Morphol 198:119-130.

Kemp TS. 2005. The Origin and Evolution of Mammals. London: Oxford University Press.

Kielan-Jaworowska Z, Cifelli RL, and Luo Z. 2004. Mammals from the Age of Dinosaurs. New York: Columbia University Press.

Ksepka DT, Fordyce RE, Ando T, and Jones CM. 2012. New fossil penguins (Aves, Sphenisciformes) from the Oligocene of New Zealand reveal the skeletal plan of stem penguins. Journal of Vertebrate Paleontology 32:235-254.

Langley-Hobbs SJ. 2009. Survey of 52 fractures of the patella in 34 cats. Vet Rec 164:80-86.

Lessertisseur J, and Saban R. 1867. Squelette appendiculaire. In: Grasse P, ed. Traite de Zoologie, anoatomie, systematique, biologie. Paris: Masson.

Lewis OJ. 1958. The tubercle of the tibia. J Anat 92:587.

Livezey BC, and Zusi RL. 2006. Higher-order phylogeny of modern birds (Theropoda, Aves: Neornithes) based on comparative anatomy: I. - Methods and characters. Bulletin of the Carnegie Museum of Natural History 37:1-556.

Lovejoy CO. 2007. The natural history of human gait and posture. Part 3. The knee. Gait Posture 25:325-341.

Lucas FA. 1903. Notes on the osteology and relationships of the fossil birds of the genera Hesperornis, Hargeria, Baptornis and Diatryma. Proceedings of the United States National Museum 26:546-556.

Luo Z-L. 2007a. Successive Diversifications in Early Mammalian Evolution. In: Anderson JS, and Sues H-D, eds. Major Transitions in Vertebrate Evolution. Bloomington: Indiana University Press.

Luo ZX. 2007b. Transformation and diversification in early mammal evolution. Nature 450:1011-1019.

Luo Z, and Ji Q. 2005. New study on dental and skeletal features of the Cretaceous "symmetrodontan" mammal Zhangheotherium. J Mammal Evol 12:337-357.

Luo ZX, and Wible JR. 2005. A Late Jurassic digging mammal and early mammalian diversification. Science 308:103-107.

Luo Z, Kielan-Jaworowska Z, and Cifelli RL. 2002. In quest for a phylogeny of Mesozoic mammals. Acta Palaeontologica Polonica 47:1-78.

Luo ZX, Ji Q, Wible JR, and Yuan CX. 2003. An Early Cretaceous tribosphenic mammal and metatherian evolution. Science 302:1934-1940.

Luo ZX, Yuan CX, Meng QJ, and Ji Q. 2011. A Jurassic eutherian mammal and divergence of marsupials and placentals. Nature 476:442-445.

Luo ZX, Gatesy SM, Jenkins FA, Jr., Amaral WW, and Shubin NH. 2015a. Mandibular and dental characteristics of Late Triassic mammaliaform Haramiyavia and their ramifications for basal mammal evolution. Proc Natl Acad Sci U S A 112:E7101-7109.

Luo ZX, Meng QJ, Ji Q, Liu D, Zhang YG, and Neander AI. 2015b. Mammalian evolution. Evolutionary development in basal mammaliaforms as revealed by a docodontan. Science 347:760-764.

Madar SI, Thewissen JGM, and Hussain ST. 2002. Additional holotype remains of Ambulocetus natans (Cetacea, Ambulocetidae), and their implications for locomotion in early whales. Journal of Vertebrate Paleontology 22:405-422.

Maddison WP, and Maddison DR. 2017. Mesquite: a modular system for evolutionary analysis. http://mesquiteproject.org

Maisano JA. 2002a. Postnatal skeletal ontogeny in Callisaurus draconoides and Uta stansburiana (Iguania: Phrynosomatidae). J Morphol 251:114-139. 
1200 Maisano JA. 2002b. Postnatal skeletal ontogeny in five Xantusiids (Squamata: Scleroglossa). $J$

1201

1202

1203

1204

1205

1206

1207

1208

1209

1210

1211

1212

1213

1214

1215

1216

1217

1218

1219

1220

1221

1222

1223

1224

1225

1226

1227

1228

1229

1230

1231

1232

1233

1234

1235

1236

1237

1238

1239

1240

1241

1242

1243

1244

1245

1246

1247

1248 Morphol 254:1-38.

Marivaux L, Adnet S, Benammi M, Tabuce R, and Benammi M. 2016. Anomaluroid rodents from the earliest Oligocene of Dakhla, Morocco, reveal the long-lived and morphologically conservative pattern of the Anomaluridae and Nonanomaluridae during the Tertiary in Africa. Journal of Systematic Palaeontology:1-31.

Marsh OC. 1875. Odontornithes, or birds with teeth. American Naturalist 9:625-631.

Martin LD. 1984. A new Hesperornithid and the relationships of the Mesozoic birds. Transactions of the Kansas Academy of Science 87:141-150.

Martin LD, and Tate J. 1976. The skeleton of Baptornis avenus. Smithsonian Contributions to Paleobiology 27:35-66.

Matthew WD. 1906. The osteology of Sinopa, a creodont mammal of the middle Eocene. Proceedings of the United States National Museum 30:203-233.

McKenna MC, and Bell SK. 1997. Classification of Mammals: Above the Species Level. New York: Columbia University Press.

Meng QJ, Ji Q, Zhang YG, Liu D, Grossnickle DM, and Luo ZX. 2015. Mammalian evolution. An arboreal docodont from the Jurassic and mammaliaform ecological diversification. Science 347:764-768.

Meredith RW, Janecka JE, Gatesy J, Ryder OA, Fisher CA, Teeling EC, Goodbla A, Eizirik E, Simao TL, Stadler T, Rabosky DL, Honeycutt RL, Flynn JJ, Ingram CM, Steiner C, Williams TL, Robinson TJ, Burk-Herrick A, Westerman M, Ayoub NA, Springer MS, and Murphy WJ. 2011. Impacts of the Cretaceous Terrestrial Revolution and KPg extinction on mammal diversification. Science 334:521-524.

Meredith RW, Westerman M, and Springer M. 2008a. A timescale and phylogeny for "Bandicoots" (Peramelemorphia, Marsupialia) based on sequences for five nuclear genes. Molecular Phylogenetics and Evolution 47:1-20.

Meredith RW, Westerman M, and Springer MS. 2008b. A timescale and phylogeny for "bandicoots" (Peramelemorphia: Marsupialia) based on sequences for five nuclear genes. Mol Phylogenet Evol 47:1-20.

Merida-Velasco JA, Sanchez-Montesinos I, Espin-Ferra J, Merida-Velasco JR, RodriguezVazquez JF, and Jimenez-Collado J. 1997a. Development of the human knee joint ligaments. Anat Rec 248:259-268.

Merida-Velasco JA, Sanchez-Montesinos I, Espin-Ferra J, Rodriguez-Vazquez JF, MeridaVelasco JR, and Jimenez-Collado J. 1997b. Development of the human knee joint. Anat $\operatorname{Rec} 248: 269-278$.

Mikic B, Johnson TL, Chhabra AB, Schalet BJ, Wong M, and Hunziker EB. 2000. Differential effects of embryonic immobilization on the development of fibrocartilaginous skeletal elements. Journal of Rehabilitation Research and Development 37:127-133.

Mottershead S. 1988. Sesamoid bones and cartilages: an enquiry into their function. Clinical Anatomy 1:59-62.

Murray P. 1984. Furry egg layers: the monotreme radiation. In: Archer M, and Clayton G, eds. Vertebrate Zoogeography and Evolution in Australasia. Carlisle: Hesperian press.

Musser AM. 2003. Review of the monotreme fossil record and comparison of palaeontological and molecular data. Comp Biochem Physiol A Mol Integr Physiol 136:927-942.

Neuweiler G. 2000. The Biology of Bats. Oxford: Oxford University Press.

Ni X, Gebo DL, Dagosto M, Meng J, Tafforeau P, Flynn JJ, and Beard KC. 2013. The oldest known primate skeleton and early haplorhine evolution. Nature 498:60-64.

Norell MA, and Clarke JA. 2001. Fossil that fills a critical gap in avian evolution. Nature 409:181-184. 
1249

1250

1251

1252

1253

1254

1255

1256

1257

1258

1259

1260

1261

1262

1263

1264

1265

1266

1267

1268

1269

1270

1271

1272

1273

1274

1275

1276

1277

1278

1279

1280

1281

1282

1283

1284

1285

1286

1287

1288

1289

1290

1291

1292

1293

1294

1295

Nowlan NC, Bourdon C, Dumas G, Tajbakhsh S, Prendergast PJ, and Murphy P. 2010a. Developing bones are differentially affected by compromised skeletal muscle formation. Bone 46:1275-1285.

Nowlan NC, Sharpe J, Roddy KA, Prendergast PJ, and Murphy P. 2010b. Mechanobiology of embryonic skeletal development: Insights from animal models. Birth Defects Res $C$ Embryo Today 90:203-213.

O'Leary MA, Bloch JI, Flynn JJ, Gaudin TJ, Giallombardo A, Giannini NP, Goldberg SL, Kraatz BP, Luo ZX, Meng J, Ni X, Novacek MJ, Perini FA, Randall ZS, Rougier GW, Sargis EJ, Silcox MT, Simmons NB, Spaulding M, Velazco PM, Weksler M, Wible JR, and Cirranello AL. 2013. The placental mammal ancestor and the post-K-Pg radiation of placentals. Science 339:662-667.

O'Leary MA, and Gatesy J. 2008. Impact of increased character sampling on the phylogeny of Cetartiodactyla (Mammalia): combined analysis including fossils. Cladistics 24:397-442.

Ogden JA. 1984. Radiology of postnatal skeletal development. X. Patella and tibial tuberosity. Skeletal Radiol 11:246-257.

Osborne AC, Lamb KJ, Lewthwaite JC, Dowthwaite GP, and Pitsillides AA. 2002. Short-term rigid and flaccid paralyses diminish growth of embryonic chick limbs and abrogate joint cavity formation but differentially preserve pre-cavitated joints. J Musculoskelet Neuronal Interact 2:448-456.

Owen R. 1866. On the Anatomy of Vertebrates. Cambridge: Cambridge University Press.

Padykula HA, and Taylor JM. 1976. Ultrastructural evidence for loss of the trophoblastic layer in the chorioallantoic placenta of Australian bandicoots (Marsupialia: Peramelidae). Anat Rec 186:357-385.

Pailthorpe CA, Milner S, and Sims MM. 1991. Is patellectomy compatible with an Army career? J R Army Med Corps 137:76-79.

Palastanga N, Field D, and Soames R. 2006. Anatomy and Human Movement: Structure and Function: Butterworth-Heinemann.

Parmar VK, Patel KB, Desai MC, Mistry JN, and Chaudhary SS. 2009. Radiographic study on the first appearance of ossification centres of bones in the goat fetuses : the pelvic limb. Indian Journal of Field Veterinarians 4:6-10.

Patton JT, and Kaufman MH. 1995. The timing of ossification of the limb bones, and growth rates of various long bones of the fore and hind limbs of the prenatal and early postnatal laboratory mouse. J Anat 186:175-185.

Pearson K, and Davin AG. 1921a. On the sesamoids of the knee joint. Biometrika 13:133-175.

Pearson K, and Davin AG. 1921b. On the sesamoids of the knee joint. Part II. Evolution of the sesamoids. Biometrika 13:350-400.

Pierce SE, Clack JA, and Hutchinson JR. 2012. Three-dimensional limb joint mobility in the early tetrapod Ichthyostega. Nature 486:523-526.

Pina M, Almecija S, Alba DM, O'Neill MC, and Moya-Sola S. 2014. The Middle Miocene ape Pierolapithecus catalaunicus exhibits extant great ape-like morphometric affinities on its patella: inferences on knee function and evolution. PLoS One 9:e91944.

Pinna MC. 1991. Concepts and tests of homology in the cladistic paradigm. Cladistics 7:367-394.

Polly PD. 2007. Limbs in Mammalian Evolution. In: Hall BK, ed. Fins into Limbs. Chicago: University of Chicago.

Ralphs JR, Benjamin M, and Thornett A. 1991. Cell and matrix biology of the suprapatella in the rat: a structural and immunocytochemical study of fibrocartilage in a tendon subject to compression. Anat Rec 231:167-177. 
1296

1297

1298

1299

1300

1301

1302

1303

1304

1305

1306

1307

1308

1309

1310

1311

1312

1313

1314

1315

1316

1317

1318

1319

1320

1321

1322

1323

1324

1325

1326

1327

1328

1329

1330

1331

1332

1333

1334

1335

1336

1337

1338

1339

1340

1341

1342

1343

1344
Ralphs JR, Benjamin M, Waggett AD, Russell DC, Messner K, and Gao J. 1998. Regional differences in cell shape and gap junction expression in rat Achilles tendon: relation to fibrocartilage differentiation. J Anat 193:215-222.

Ralphs JR, Tyers RN, and Benjamin M. 1992. Development of functionally distinct fibrocartilages at two sites in the quadriceps tendon of the rat: the suprapatella and the attachment to the patella. Anat Embryol 185:181-187.

Raymond KR, and Prothero DR. 2012. Comparative variability of intermembranous and endochondral bones in Pleistocene mammals. Palaeontologia Electronica.

Reese S, Pfuderer UR, Bragulla H, Loeffler K, and Budras KD. 2001. Topography, structure and function of the patella and the patelloid in marsupials. Anat Histol Embryol 30:289-294.

Regnault S, Jones ME, Pitsillides AA, and Hutchinson JR. 2016. Anatomy, morphology and evolution of the patella in squamate lizards and tuatara (Sphenodon punctatus). J Anat 228:864-876.

Regnault S, Pitsillides AA, and Hutchinson JR. 2014. Structure, ontogeny and evolution of the patellar tendon in emus (Dromaius novaehollandiae) and other palaeognath birds. PeerJ 2:e711.

Rieppel O. 1989. The hindlimb of Macrocnemus bassanii (Nopsca) (Reptilia, Diapsida): development and functional anatomy. Journal of Vertebrate Paleontology 9:373-387.

Riskin DK, and Hermanson JW. 2005. Biomechanics: independent evolution of running in vampire bats. Nature 434:292.

Romer AS. 1976. Osteology of the Reptiles. Chicago: University of Chicago.

Rook DL, and Hunter JP. 2014. Rooting around the eutherian family Tree: the origin and eelations of the Taeniodonta. Journal of Mammalian Evolution 21:75-91.

Rose KD. 1982. Skeleton of Diacodexis, oldest known artiodactyl. Science 216:621-623.

Rose KD. 1999. Postcranial skeletons of Eocene Leptictidae (Mammalia), and its implications for behavior and relationships. Journal of Vertebrate Paleontology 19:355-372.

Rose KD. 2006. The Beginning of the Age of Mammals. Baltimore: Johns Hopkins University Press.

Rose KD, and Walker A. 1985. The skeleton of early Eocene Cantius, oldest lemuriform primate. American Journal of Physical Anthropology 66:73-89.

Rot-Nikcevic I, Reddy T, Downing KJ, Belliveau AC, Hallgrimsson B, Hall BK, and Kablar B. 2006. Myf5-/- :MyoD-/- amyogenic fetuses reveal the importance of early contraction and static loading by striated muscle in mouse skeletogenesis. Dev Genes Evol 216:1-9.

Rowe T. 1988. Definition, diagnosis and origin of Mammalia. Journal of Vertebrate Paleontology 8:241-264.

Rowe T, Rich TH, Vickers-Rich P, Springer M, and Woodburne MO. 2008. The oldest platypus and its bearing on divergence timing of the platypus and echidna clades. Proc Natl Acad Sci U S A 105:1238-1242.

Samuels JX, Meachen JA, and Sakai SA. 2013. Postcranial morphology and the locomotor habits of living and extinct Carnivorans. J Morphol 274:121-146.

Sanchez-Villagra M, Ladeveze S, Horovitz I, Argot C, Hooker JJ, Macrini TE, Martin T, MooreFay S, de Muizon C, Schmelzle T, and Asher RJ. 2007. Exceptionally preserved North American Paleogene metatherians: adaptations and discovery of a major gap in the opossum fossil record. Biol Lett 3:318-322.

Sarin VK, and Carter DR. 2000. Mechanobiology and joint conformity regulate endochondral ossification of sesamoids. J Orthop Res 18:706-712.

Sarin VK, Erickson GM, Giori NJ, Bergman AG, and Carter DR. 1999. Coincident development of sesamoid bones and clues to their evolution. Anat Rec 257:174-180.

Scapinelli R. 1963. Sesamoid bones in the ligamentum nuchae of man. J Anat 97:417-422. 
1345 Schaal S, and Ziegler W. 1992. Messel: An insight into the history of life and of the earth.

1346 London: Clarendon Press.

1347

1348

1349

1350

1351

1352

1353

1354

1355

1356

1357

1358

1359

1360

1361

1362

1363

1364

1365

1366

1367

1368

1369

1370

1371

1372

1373

1374

1375

1376

1377

1378

1379

1380

1381

1382

1383

1384

1385

1386

1387

1388

1389

1390

1391

Schlosser M. 1887. Die Affen, Lemuren, Chiropteren, Insectivoren, Marsupialen, Creodonten und Carnivoren des europaischen Tertiars und deren Beziehungen zu ihren lebenden und fossilen aussereuropaischen Verwandten. In: Mojsisovics Ev, and Neumayr M, eds. Beitrage zur Palaontologie osterreich-ungarns und des orients. Wien: Holder, 1-162.

Schutt WA, and Simmons NB. 2006. Quadrupedal Bats: Form, Function and Evolution. In: Zubaid A, McCracken GF, and Kunz TH, eds. Functional and Evolutionary Ecology of Bats. Oxford: Oxford University Press.

Schuurman SO, Kersten W, and Weijs WA. 2003. The equine hind limb is actively stabilized during standing. J Anat 202:355-362.

Shubin NH, Daeschler EB, and Jenkins FA, Jr. 2006. The pectoral fin of Tiktaalik roseae and the origin of the tetrapod limb. Nature 440:764-771.

Shufeldt RW. 1884. Concerning some of the forms assumed by the patella in birds. Proceedings of the United States National Museum 7:324-331.

Silcox MT, Bloch JI, Boyer DM, and Houde P. 2010. Cranial anatomy of Paleocene and Eocene Labidolemur kayi (Mammalia: Apatotheria), and the relationships of the Apatemyidae to other mammals. Zoological Journal of the Linnean Society 160:773-825.

Silcox MT. 2007. Primate Taxonomy, Plesiadapiforms, and Approaches to Primate Origins. In: Ravoso MJ, and Dagosto M, eds. Primate Origins: Adaptations and Evolution. New York: Springer, 143-178.

Simmons NB, Seymour KL, Habersetzer J, and Gunnell GF. 2008. Primitive early Eocene bat from Wyoming and the evolution of flight and echolocation. Nature 451:818-821.

Smith BJ, Holladay SD, and Smith SA. 1995. Patella of selected bats: patterns of occurrence or absence and associated modifications of the quadriceps femoris tendon. Anat Rec 242:575-580.

Smith HF, Parker W, Kotze SH, and Laurin M. 2013. Multiple independent appearances of the cecal appendix in mammalian evolution and an investigation of related ecological and anatomical factors. Comptes Rendus Palevol.

Song S, Liu L, Edwards SV, and Wu S. 2012. Resolving conflict in eutherian mammal phylogeny using phylogenomics and the multispecies coalescent model. Proc Natl Acad Sci USA 109:14942-14947.

Spark C, and Dawson AB. 1928. The order and time of appearance of centers of ossification in the fore and hind limbs of the albino rat, with special reference to the possible influence of the sex factor. Developmental Dynamics 41:411-445.

Spaulding M, O'Leary MA, and Gatesy J. 2009. Relationships of Cetacea (Artiodactyla) among mammals: increased taxon sampling alters interpretations of key fossils and character evolution. PLoS One 4:e7062.

Springer MS, Burk-Herrick A, Meredith R, Eizirik E, Teeling E, O'Brien SJ, and Murphy WJ. 2007. The adequacy of morphology for reconstructing the early history of placental mammals. Syst Biol 56:673-684.

Springer MS, Murphy WJ, Eizirik E, and O'Brien SJ. 2003. Placental mammal diversification and the Cretaceous-Tertiary boundary. Proc Natl Acad Sci USA 100:1056-1061.

Suarez C, Forasiepi AM, Goin FJ, and Jaramillo C. 2016. Insights into the Neotropics prior to the Great American Biotic Interchange: new evidence of mammalian predators from the Miocene of Northern Colombia. Journal of Vertebrate Paleontology 36:e1029581.

Sweetnam R. 1964. Patellectomy. Postgrad Med J 40:531-535. 
1392

1393

1394

1395

1396

1397

1398

1399

1400

1401

1402

1403

1404

1405

1406

1407

1408

1409

1410

1411

1412

1413

1414

1415

1416

1417

1418

1419

1420

1421

1422

1423

1424

1425

1426

1427

1428

1429

1430

1431

1432

1433

1434

1435

1436

1437

1438

1439

1440

Szalay FS, and Sargis EJ. 2001. Model-based analysis of postcranial osteology of marsupials from the Palaeocene of Itaboraí (Brazil) and the phylogenetics and biogeography of Metatheria. Geodiversitas 23:139-302.

Szalay FS, Tattersall I, and Decker RL. 1975. Phyogenetic Relationships of Pleasiadapis Postcranial Evidence. In: Szalay FS, ed. Approaches to Primate Paleobiology. Basel: Karger.

Szalay FS, and Trofimov BA. 1996. The Mongolian late Cretaceous Asiatherium, and the early phylogeny and paleobiogeography of metatheria. Journal of Vertebrate Paleontology 16:474-509.

Tecklenburg K, Dejour D, Hoser C, and Fink C. 2006. Bony and cartilaginous anatomy of the patellofemoral joint. Knee Surg Sports Traumatol Arthrosc 14:235-240.

Thewissen JG. 1990. Evolution of Paleocene and Eocene Phenacodontidae (Mammalia, Condylarthra). Papers on Paleontology University of Michigan 29:1-107.

Thewissen JG, Cooper LN, Clementz MT, Bajpai S, and Tiwari BN. 2007. Whales originated from aquatic artiodactyls in the Eocene epoch of India. Nature 450:1190-1194.

Thewissen JG, Williams EM, Roe LJ, and Hussain ST. 2001. Skeletons of terrestrial cetaceans and the relationship of whales to artiodactyls. Nature 413:277-281.

Thompson D. 1890. On the systematic position of Hesperornis. Studies from the Museum of Zoology in University College, Dundee 1:97-112.

Toumi H, Higashiyama I, Suzuki D, Kumai T, Bydder G, McGonagle D, Emery P, Fairclough J, and Benjamin M. 2006. Regional variations in human patellar trabecular architecture and the structure of the proximal patellar tendon enthesis. J Anat 208:47-57.

Toumi H, Larguech G, Filaire E, Pinti A, and Lespessailles E. 2012. Regional variations in human patellar trabecular architecture and the structure of the quadriceps enthesis: a cadaveric study. J Anat 220:632-637.

Tria AJ, Jr., and Alicea JA. 1995. Embryology and Anatomy of the Patella. In: Scuderi GR, ed. The Patella. New York: Springer-Verlag.

Uhen MD. 2004. Form. function and anatomy of Dorudon atrox (Mammalia, Cetacea): an archaeocete from the middle to late Eocene of Egypt. University of Michigan Papers on Palaeontology. Ann Arbor: University of Michigan.

Valois H. 1917. La valeur morphologique de la rotule chez les mammifères. Bulletins et Mémoires de la Société d'anthropologie de Paris 8:1-34.

Vanden Berge JL, and Storer RW. 1995. Intratendinous ossification in birds: a review. J Morphol 226:47-77.

Vickaryous MK, and Olson WM. 2007. Sesamoids and Ossicles in the Appendicular Skeleton. In: Hall BK, ed. Fins into Limbs. Chicago: University of Chicago.

Walji AH, and Fasana FV. 1983. Structural and functional organization of the suprapatella in two cercopithecines. J Morphol 176:113-119.

Walmsley R. 1940. Development of the patella. J Anat 73:360-368.

Walsh SA, and Suarez ME. 2006. New penguin remains from the Pliocene of northern Chile. Historical Biology: An International Journal of Paleobiology 18:119-130.

Warren WC, Hillier LW, Marshall Graves JA, Birney E, Ponting CP, Grutzner F, Belov K, Miller W, Clarke L, Chinwalla AT, Yang SP, Heger A, Locke DP, Miethke P, Waters PD, Veyrunes F, Fulton L, Fulton B, Graves T, Wallis J, Puente XS, Lopez-Otin C, Ordonez GR, Eichler EE, Chen L, Cheng Z, Deakin JE, Alsop A, Thompson K, Kirby P, Papenfuss AT, Wakefield MJ, Olender T, Lancet D, Huttley GA, Smit AF, Pask A, Temple-Smith P, Batzer MA, Walker JA, Konkel MK, Harris RS, Whittington CM, Wong ES, Gemmell NJ, Buschiazzo E, Vargas Jentzsch IM, Merkel A, Schmitz J, Zemann A, Churakov G, Kriegs JO, Brosius J, Murchison EP, Sachidanandam R, Smith C, Hannon GJ, Tsend-Ayush E, 
1441

1442

1443

1444

1445

1446

1447

1448

1449

1450

1451

1452

1453

1454

1455

1456

1457

1458

1459

1460

1461

1462

1463

1464

1465

1466

1467

1468

1469

1470

1471

1472

1473

1474

1475

1476

1477

1478

1479

1480

1481

1482

McMillan D, Attenborough R, Rens W, Ferguson-Smith M, Lefevre CM, Sharp JA, Nicholas KR, Ray DA, Kube M, Reinhardt R, Pringle TH, Taylor J, Jones RC, Nixon B, Dacheux JL, Niwa H, Sekita Y, Huang X, Stark A, Kheradpour P, Kellis M, Flicek P, Chen Y, Webber C, Hardison R, Nelson J, Hallsworth-Pepin K, Delehaunty K, Markovic C, Minx P, Feng Y, Kremitzki C, Mitreva M, Glasscock J, Wylie T, Wohldmann P, Thiru P, Nhan MN, Pohl CS, Smith SM, Hou S, Nefedov M, de Jong PJ, Renfree MB, Mardis ER, and Wilson RK. 2008. Genome analysis of the platypus reveals unique signatures of evolution. Nature 453:175-183.

Welker F, Collins MJ, Thomas JA, Wadsley M, Brace S, Cappellini E, Turvey ST, Reguero M, Gelfo JN, Kramarz A, Burger J, Thomas-Oates J, Ashford DA, Ashton PD, Rowsell K, Porter DM, Kessler B, Fischer R, Baessmann C, Kaspar S, Olsen JV, Kiley P, Elliott JA, Kelstrup CD, Mullin V, Hofreiter M, Willerslev E, Hublin J-J, Orlando L, Barnes I, and MacPhee RDE. 2015. Ancient proteins resolve the evolutionary history of Darwin's South American ungulates. Nature 522:81-84.

Wentink GH. 1978. Biokinetical analysis of the movements of the pelvic limb of the horse and the role of the muscles in the walk and the trot. Anat Embryol (Berl) 152:261-272.

Westerman M, Kear BP, Aplin K, Meredith RW, Emerling C, and Springer MS. 2012. Phylogenetic relationships of living and recently extinct bandicoots based on nuclear and mitochondrial DNA sequences. Mol Phylogenet Evol 62:97-108.

Wible JR, Rougier GW, and Novacek MJ. 2005. Anatomical evidence for superordinal/ordinal eutherian taxa in the Cretaceous. The Rise of Placental Mammals. Baltimore: Johns Hopkins University Press, 15-36.

Wible JR, Rougier GW, Novacek MJ, and Asher RJ. 2007. Cretaceous eutherians and Laurasian origin for placental mammals near the K/T boundary. Nature 447:1003-1006.

Wilson DE, and Reeder DM. 2005. Mammal Species of the World. 3rd ed. Baltimore: Johns Hopkins University Press.

Wilson GP, Evans AR, Corfe IJ, Smits PD, Fortelius M, and Jernvall J. 2012. Adaptive radiation of multituberculate mammals before the extinction of dinosaurs. Nature 483:457-460.

Wren TA, Beaupre GS, and Carter DR. 2000. Mechanobiology of tendon adaptation to compressive loading through fibrocartilaginous metaplasia. J Rehabil Res Dev 37:135143.

Yuan CX, Ji Q, Meng QJ, Tabrum AR, and Luo ZX. 2013. Earliest evolution of multituberculate mammals revealed by a new Jurassic fossil. Science 341:779-783.

Zack SP, Penkrot TA, Krause DW, and Maas MC. 2005. A new apheliscine "condylarth" mammal from the late Paleocene of Montana and Alberta and the phylogeny of "hyopsodontids". Acta Palaeontologica Polonica 50:809-830.

Zalmout IS. 2008. Late Eocene sea cows (Mammalia, Sirenia) from Wadi al Hitan in the Fayum Basin, Egypt. University of Michigan.

Zheng X, Bi S, Wang X, and Meng J. 2013. A new arboreal haramiyid shows the diversity of crown mammals in the Jurassic period. Nature 500:199-202.

Zhou CF, Wu S, Martin T, and Luo ZX. 2013. A Jurassic mammaliaform and the earliest mammalian evolutionary adaptations. Nature 500:163-167. 


\section{FIGURES}

1484 Figure 1. Generalized knee showing sesamoid bones found in various mammals, although possibly no species includes all of these (patella, lunula, cyamella, fabella and parafibula). Also shown are relevant muscles, ligaments and other anatomical elements that lie close to the sesamoids of the knee joint. The knee is in medial view and the medial collateral ligament has

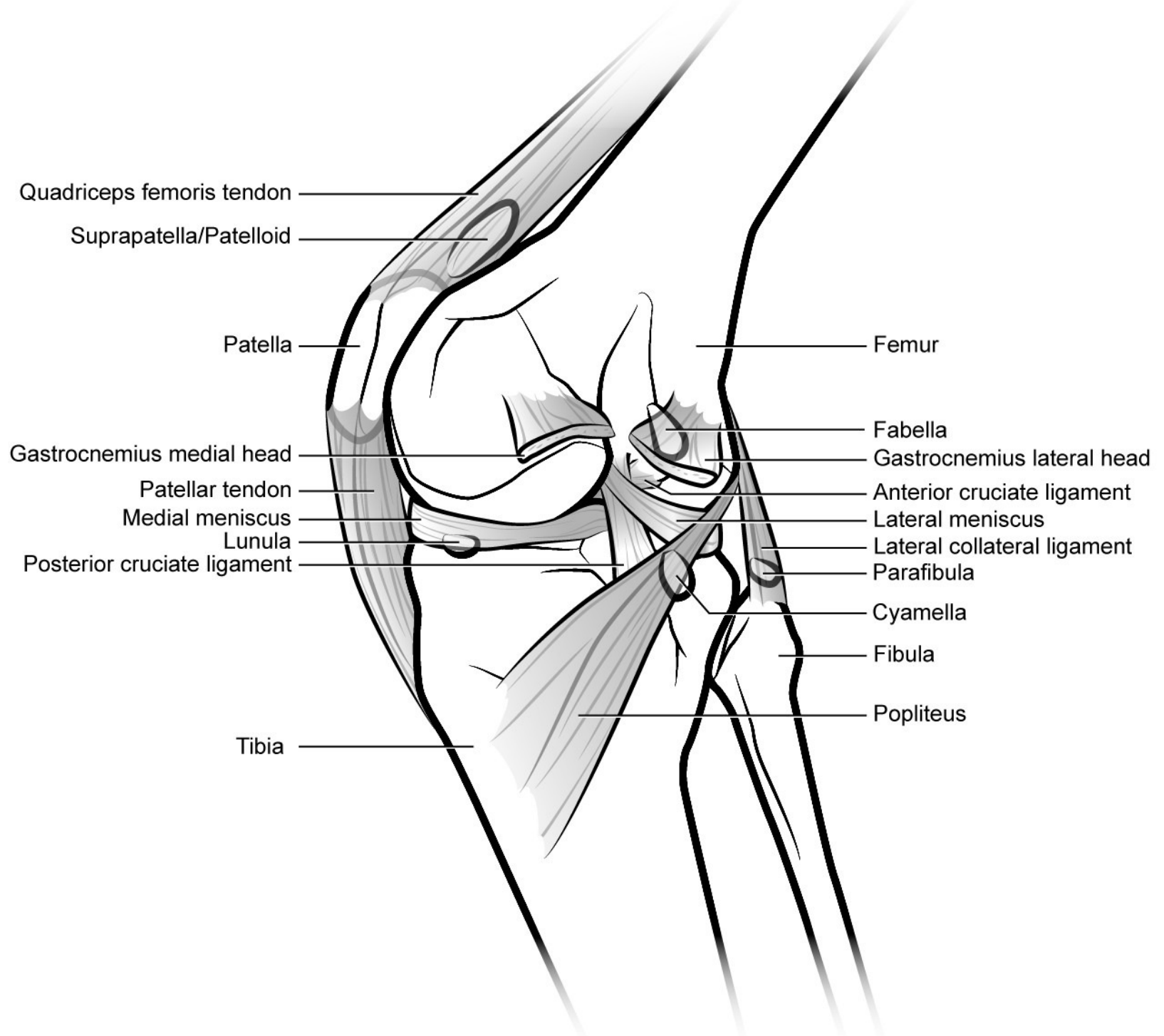


1489 Figure 2. Generalized tetrapod with anatomical/developmental axes defined for the hindlimb: $1490 \mathrm{cranial} /$ caudal (towards the head/tail respectively), proximal/distal (toward/further from the trunk respectively), dorsal/ventral (towards the back/belly respectively). Illustration: Manuela Bertoni.

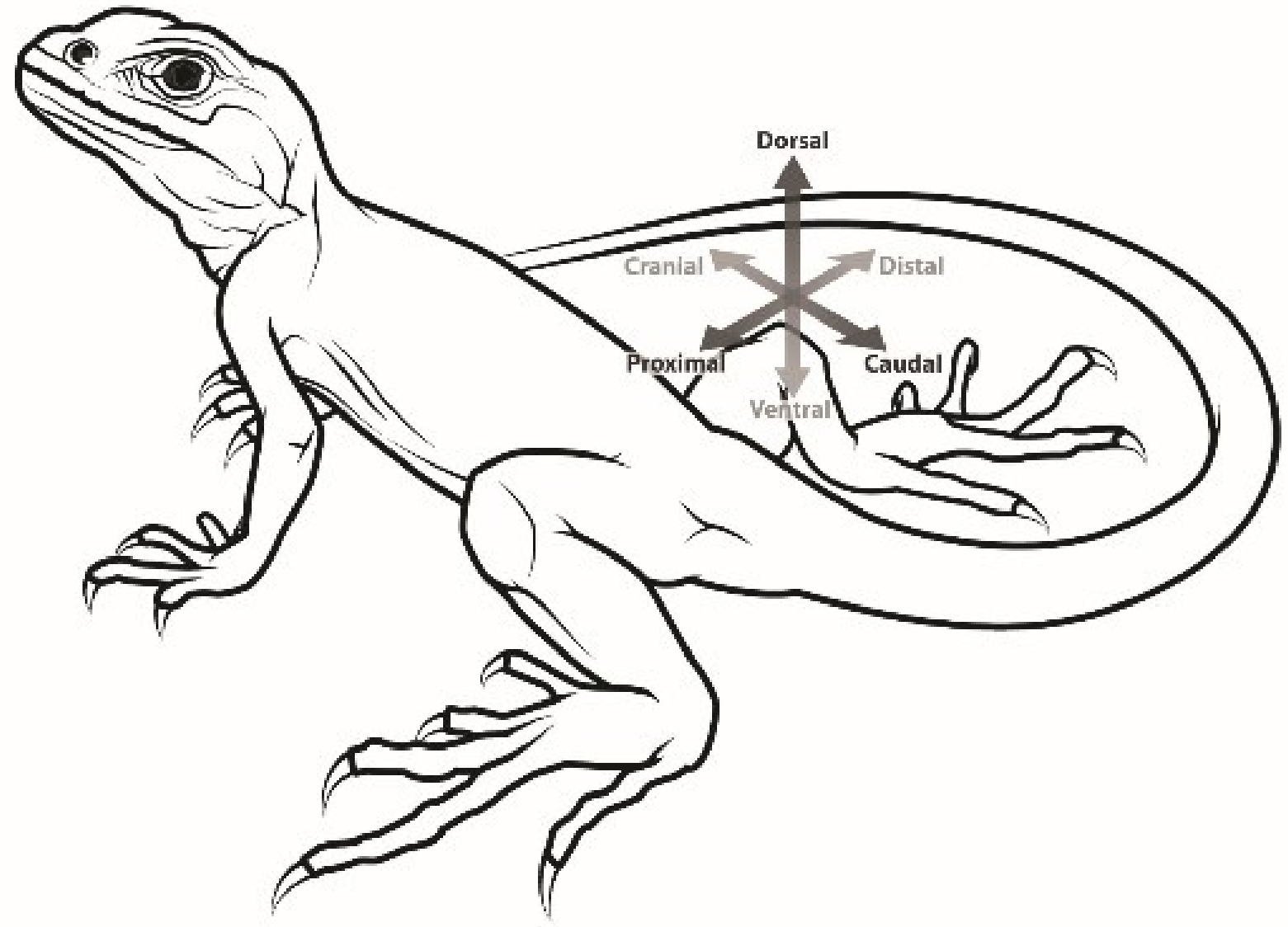


1492 Figure 3. Reconstruction of ancestral patellar states in Tetrapoda, showing the major extant 1493 clades. Reconstruction was performed using Mesquite's parsimony algorithm and unordered 1494 character states, where 0 (black) $=$ absent patella, 1 (yellow) $=$ soft tissue patella/patelloid, and 2 (blue) $=$ ossified patella; see Methods for further details. The distribution of the ossified patella among extant clades has been interpreted as three occasions of independent evolution (in Aves, 1497 Squamata, and Mammalia) (Dye, 1987, Haines, 1940), a conclusion strongly reinforced by 1498 specific fossil evidence (absence or equivocality of a patella in all outgroups). Reconstruction within Mammalia is explored in more depth in Figures 5-7. MYA= millions of years from 1500 present.

KEY

No data/ambiguous state

Absent patella

Fibrocartilage patella

Ossified patella
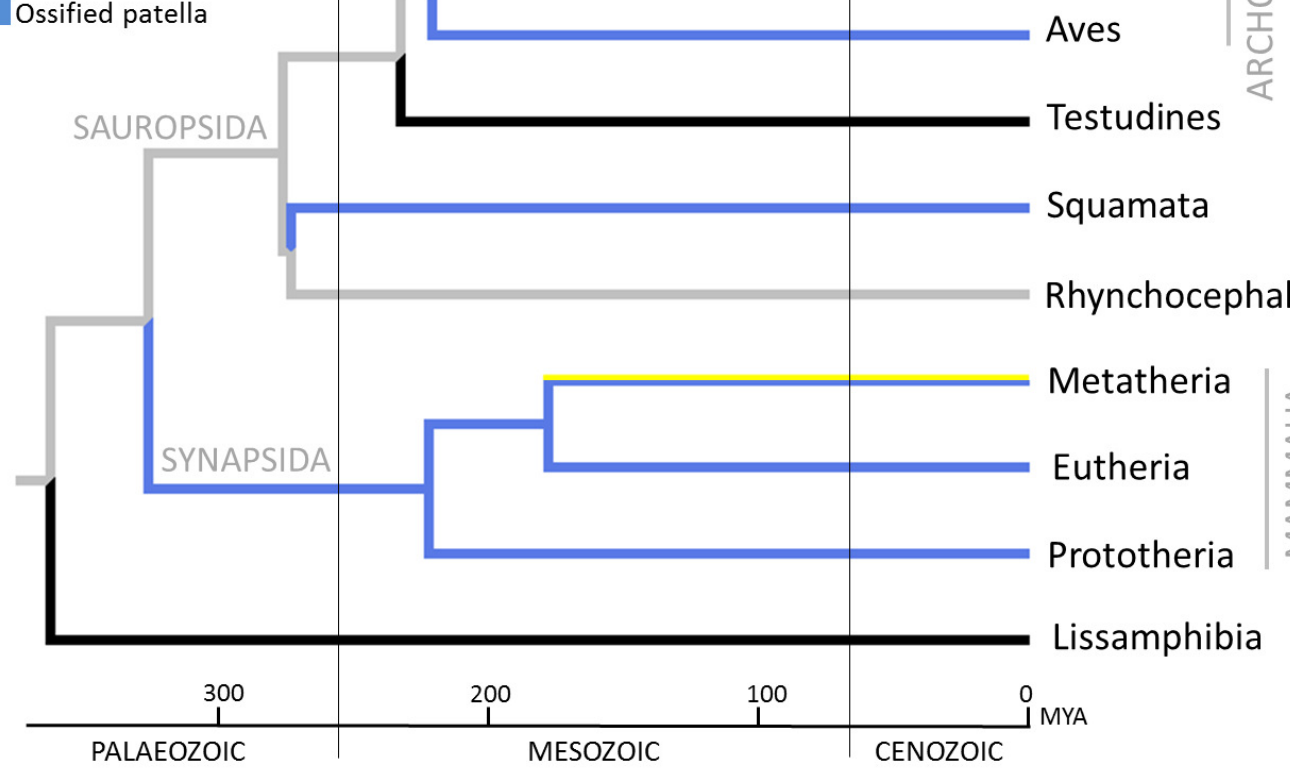
1501 Figure 4. Examples of tetrapods with or without patellae. Red arrows denote the patella. A, B. 1502 Ornithorhynchus anatinus (Monotremata: duck-billed platypus, Redpath Museum specimen 1503 2458). C, D. Tachyglossus aculeatus (Monotremata: echidna, Redpath Museum specimen 2463). 1504 E, F. Didelphis virginiana (Metatheria: North American opossum, Redpath Museum specimen 1505 5019). G, H. Procavia capensis (Eutheria: Afrotheria: Cape hyrax, uncatalogued Horniman 1506 Museum specimen, London, United Kingdom). I, knee of patient with Meier-Gorlin Syndrome 1507 (Guernsey et al. 2010). For more images of mammalian patellae (or lack thereof in some 1508 marsupials), see Figures S1-S3. 
A

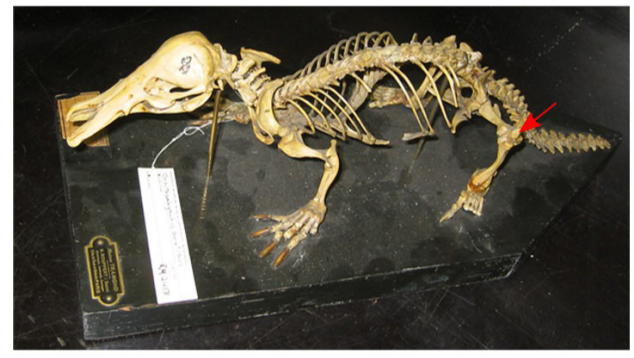

C

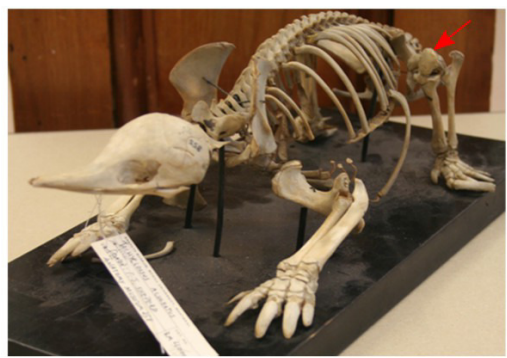

E

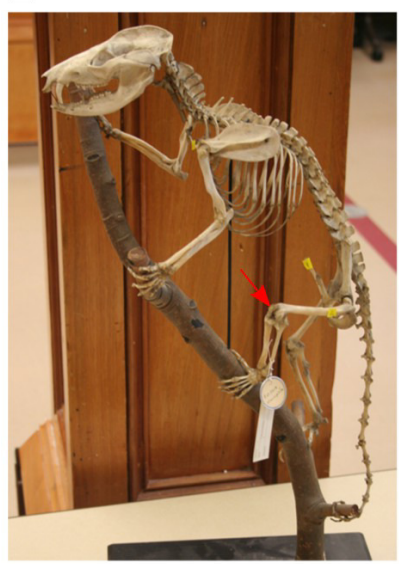

G

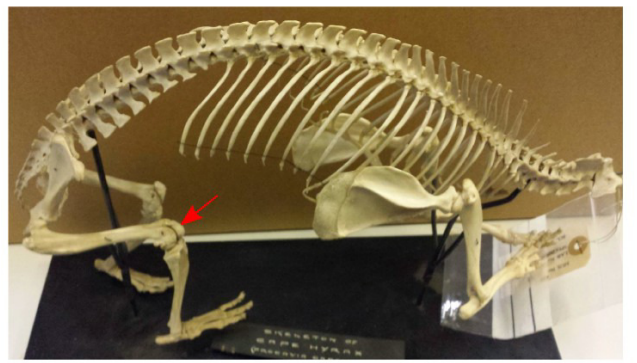

I
B

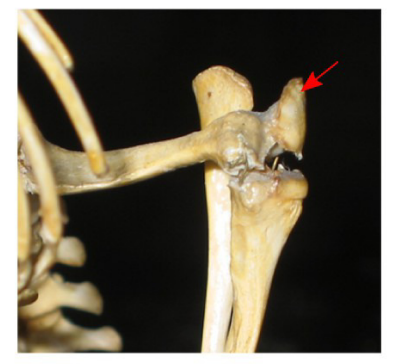

D

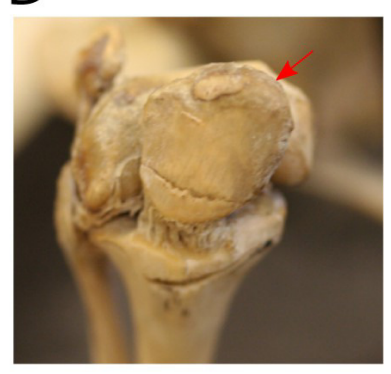

$\mathrm{F}$

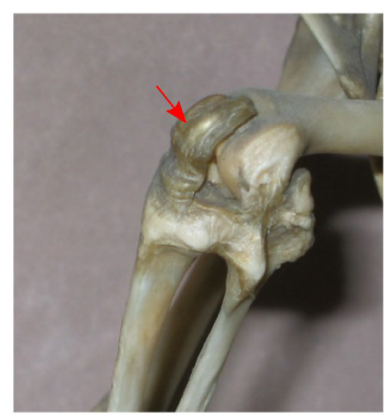

$\mathrm{H}$

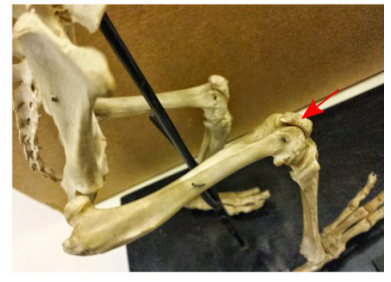


1509 Figure 5. Ancestral state reconstruction of the patella in Mesozoic mammals (see Fig. S4 for alternative tree topology). Key fossils with hindlimb material are denoted by $\uparrow$. The main tree shows a parsimony reconstruction using unordered character states, where branch colour indicates reconstructed state.

1512 Maximum likelihood gives similar results to parsimony, and likelihood values for numbered nodes are 1513 displayed (inset). Crown Metatheria and Eutheria are further explored in Figs. 6 and 7. Our results suggest 1514 that the ossified patella has evolved at least five times within Mammaliaformes.

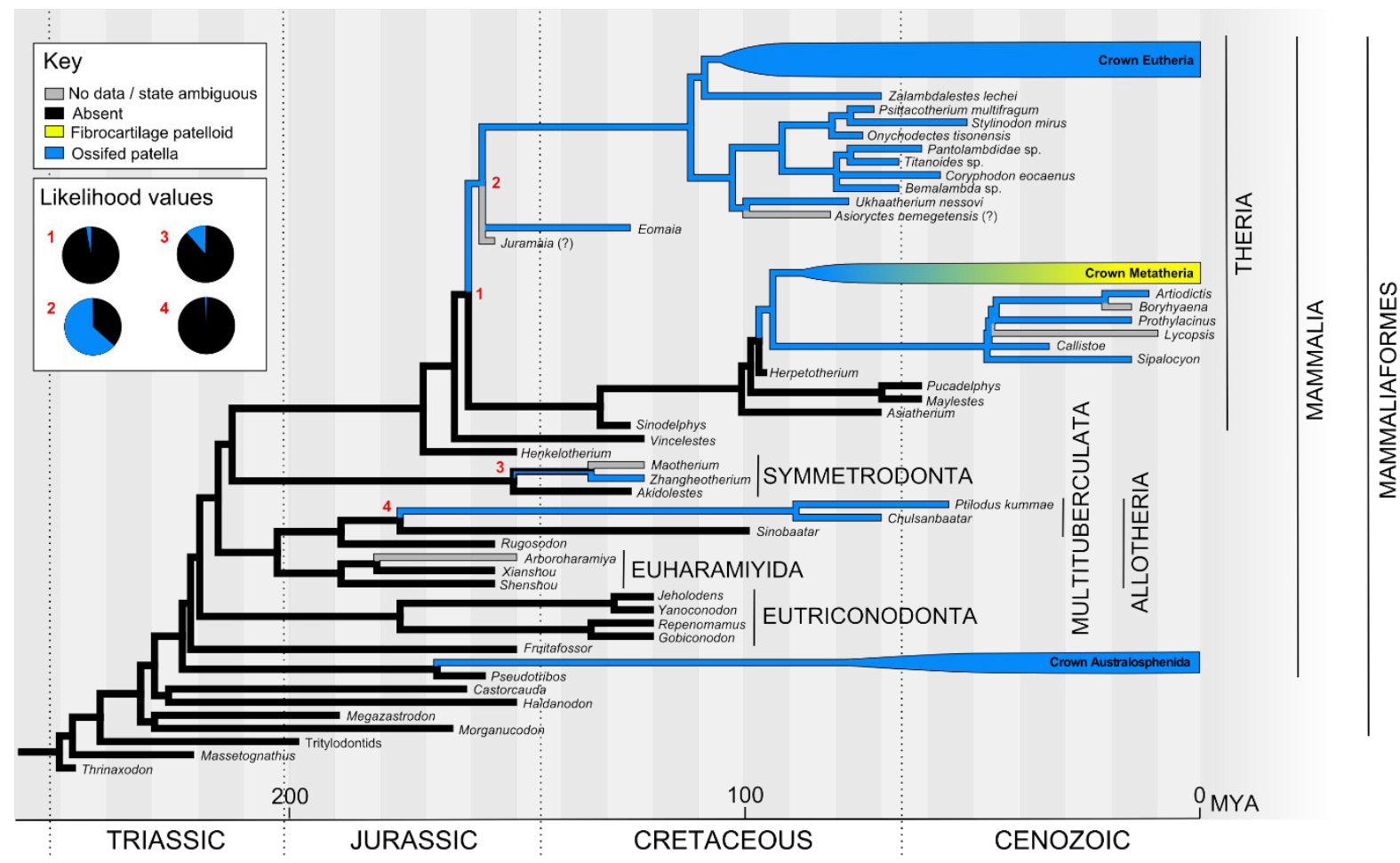


1515 Figure 6. Ancestral state reconstruction of the patella in Metatheria and related taxa. Key fossils with 1516 hindlimb material are denoted by $\dagger$. The main tree shows a parsimony reconstruction using unordered 1517 character states, where branch colour indicates reconstructed state. Likelihood values for the numbered 1518 nodes are shown (inset). Our results suggest that the ossified patella evolved once in Metatheria, with 1519 instances of loss and reversion (to a fibrocartilaginous patelloid and back).

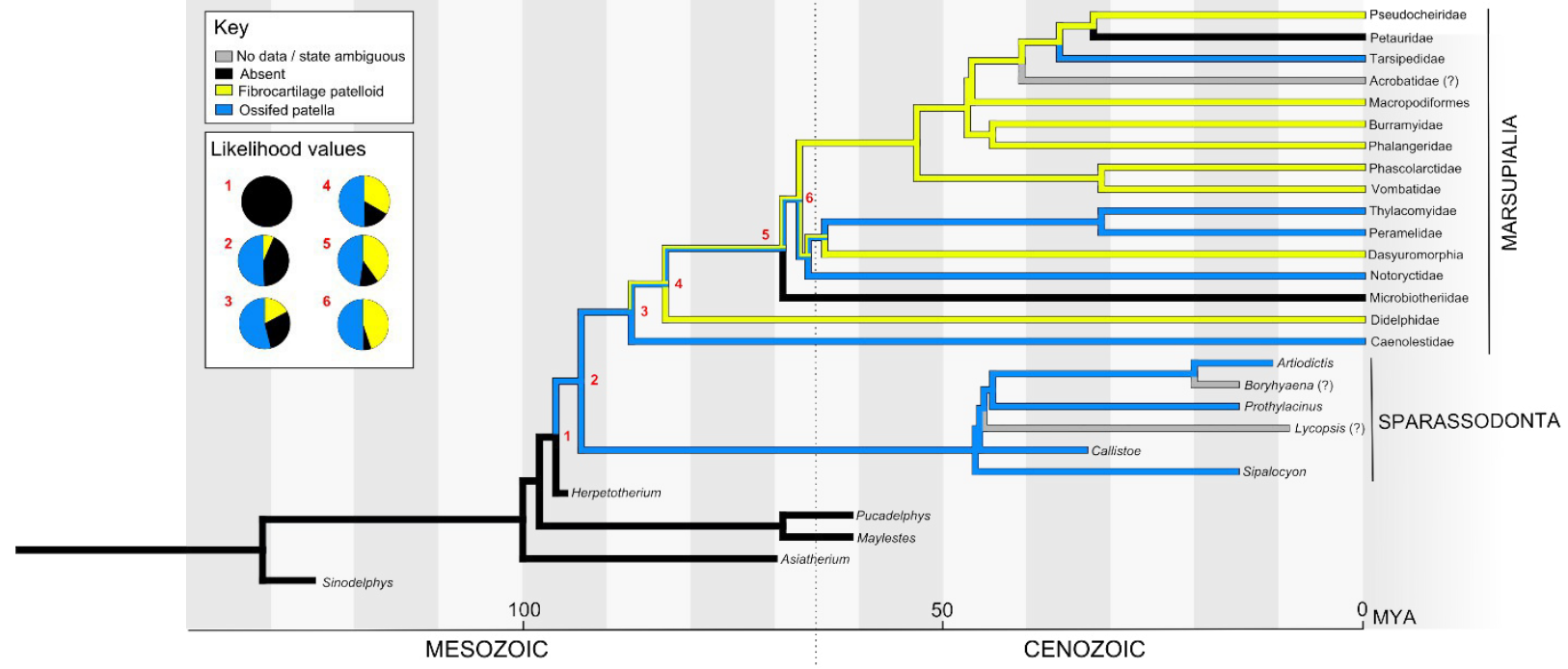


1520 Figure 7. Ancestral state reconstruction of the patella in Eutheria. Key fossils with hindlimb material are 1521 denoted by $\uparrow$. The main tree shows a parsimony reconstruction using unordered character states, where 1522 branch colour indicates the reconstructed state. Our results suggest that the ossified patella evolved only 1523 once within Eutheria and (as far as is currently known) has only been lost by the bat genus Pteropus (not 1524 counting groups which have lost hindlimbs; e.g. Trichechus manatus/crown Sirenia, Tursiops

1525 truncatus/crown Cetacea). 


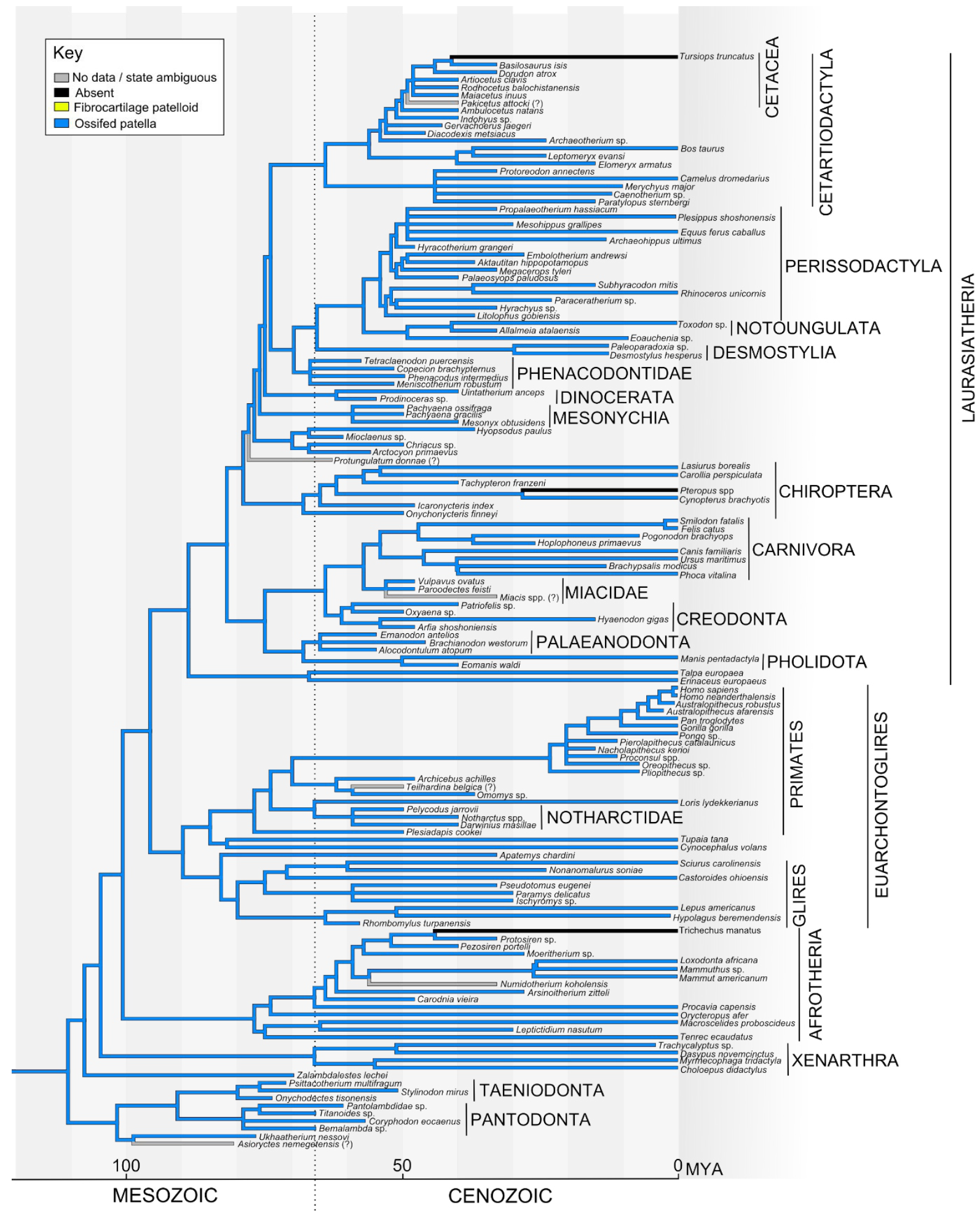

